\title{
We do not need structuralist morphemes, but we do need constituent structure
}

Ricardo Bermúdez-Otero

University of Manchester

In Daniel Siddiqi \& Heidi Harley (eds), 2016, Morphological metatheory (Linguistics Today 229), 387-430. Amsterdam: John Benjamins.

\begin{abstract}
In the prethematic high mid alternation of Spanish third-conjugation verbs, allomorph selection by phonological subcategorization in the morphology interacts with allomorph selection by phonotactic optimization in the phonology, pace Paster (2015). The cyclic locality conditions on this alternation support frameworks with stem storage (Bermúdez-Otero 2013a) or spanning (Svenonius and Haugen \& Siddiqi in this volume), and challenge single-terminal insertion. Embick's (2012) alternative analysis weakens inward cyclic locality excessively. Myler's (2015) counterproposal overgenerates and undermines the explanation of the parallel cyclic transmission of allomorphy and allosemy. Allomorphy-allosemy mismatches do occur: e.g. when English trànsp[ə]rtátion preserves the argument structure of trànspórt but not its bipedality. However, such mismatches are not generated computationally; they arise diachronically through the interplay of computation and storage (Bermúdez-Otero 2012). Theories asserting that words lack constituent structure cannot explain this fact, pace Blevins, Ackerman \& Malouf (this volume).
\end{abstract}

\section{Contents}

1. Introduction 2

2. We do not need structuralist morphemes: on stem storage 3

2.1. Stem storage avoids conspiratorial zeroes 3

2.2. Stem storage widens cyclic domains for allomorph selection just enough 6

2.2.1. Spanish third-conjugation verbs: subcategorization and phonotactic optimization 7

2.2.2. Cyclic locality in the Spanish third-conjugation alternation 15

2.3. Stem storage maintains parallel cycles of phonological and semantic interpretation 21

2.3.1. The cyclic transmission of stress-induced hiatus in Spanish denominal derivatives 22

2.3.2. The parallel cyclic transmission of allomorphy and allosemy 26

3. We need constituent structure: on the diachronic interaction of computation and storage 32

4. Conclusion 37

References 


\section{Introduction ${ }^{1}$}

J'ay trouvé que la pluspart des Sectes ont raison dans une bonne partie de ce qu'elles avancent, mais non pas tant en ce qu'elles nient.

Leibniz, letter to Nicolas Rémond, 10 January 1714

Current schools of morphology differ in the extent to which they reject the legacy of American structuralism and its vision of a combinatorics of atomic Saussurean signs. In this respect, mainstream versions of Distributed Morphology (DM) represent a relatively conservative position: DM adopts a realizational rather than incremental approach to exponence (Stump 2001: 2), but, as formulated in works like Halle \& Marantz (1993, 1994), Embick (2010), or Arregi \& Nevins (2012), the theory asserts that morphs (including zeroes) realize single syntactic terminals, and so at the point of vocabulary insertion it establishes a one-to-one mapping between exponenda and exponents. In contrast, the five chapters in this part of the volume move further away from the structuralist conception of the morpheme. Haugen \& Siddiqi, Haugen, and Svenonius reject the hypothesis of single-terminal insertion in favour of spanning, which allows a single morph to realize a set of contiguous terminals in word-syntactic structure. Far more radically, Blevins, Ackerman \& Malouf discard the idea that words have hierarchical constituent structure at all; instead, they propose a discriminative approach to morphology in the word-and-paradigm tradition. Archangeli \& Pulleyblank also advocate a major break with structuralist morphemes: they abandon underlying representations, which originate in the structuralist notion of the base form of a morpheme.

The bulk of this chapter is devoted to an extended argument against DM's hypothesis of single-terminal insertion and in favour of the spanning models proposed by Haugen \& Siddiqi, Haugen, and Svenonius, which for the relevant purposes are equivalent to the theory of stem storage set out in Bermúdez-Otero (2013a). In recent years, the debate between frameworks assuming single-terminal insertion and frameworks adopting stem storage or spanning has been pursued empirically in an arena of central concern to DM: locality conditions on allomorph selection (Embick 2010, Bobaljik 2012). Merchant (2015) shows that spanning makes better predictions in respect of linear locality. Bermúdez-Otero (2013a) makes the complementary point that stem storage makes better predictions in respect of cyclic locality. In both cases, the argument is that the local domains for allomorph selection generated in mainstream DM are too narrow, whereas theories allowing insertion into multiple terminals widen those domains just enough whilst avoiding the opposite problem of unrestricted globalism. In section 2 I reprise the argument

\footnotetext{
1 I would like to thank Patricia Cabredo Hofherr, Antonio Fábregas, Andrew Koontz-Garboden, Jason Merchant, Beata Moskal, Neil Myler, and Daniel Siddiqi for their helpful comments. None of them should be taken to endorse the contents of this paper. I alone am responsible for all errors and omissions.
} 
from Bermúdez-Otero (2013a), using different data from Spanish: namely, the alternations affecting prethematic vowels in third-conjugation verbs. In section 2.2 I show that the Embick's (2012) alternative analysis fails because it weakens inward cyclic locality in empirically unwarranted ways. In section 2.3 I go on to consider Myler's (2015) counterproposals, and I show that they undermine another of DM's programmatic goals: to explain the parallel cyclic transmission of allomorphy and allosemy (e.g. Marvin 2002: 31ff). As a supplementary result, my analysis of the Spanish third conjugation will demonstrate that phonologically conditioned allomorph selection by subcategorization in the morphology coexists with allomorph selection by phonotactic optimization in the phonology. Pace Bye (2015: 120-121) and Paster (2015: 237-240), the two mechanisms do not duplicate, but rather complement, each other.

In frameworks adopting multiple-terminal insertion there is no point in the derivation at which exponenda are paired up with exponents in a one-to-one fashion. This does represent a major departure from the structuralist conception of the morpheme. In the remainder of the chapter, however, I argue that Blevins, Ackerman \& Malouf go too far in their rejection of the legacy of American structuralism. Section 2.3.2 draws attention to the striking accuracy with which the cyclic transmission of morphophonological properties between constituents of complex words mirrors the cyclic transmission of allosemic restrictions. Section 3 shows that allomorphy and allosemy can become decorrelated in the course of historical change, but argues that such developments should be understood in terms of the interaction between computation and storage; the grammar's combinatorial engine does not generate mismatches between morphophonological cyclicity and semantic compositionality. Blevins, Ackerman \& Malouf are unable to explain this fact, since they assume that words do not have constituent structure. ${ }^{2}$

In conclusion, neither allomorphic locality nor allomorphy-allosemy mismatches can be understood without a proper account of lexical listing and its interplay with the grammar's combinatorial operations.

\section{We do not need structuralist morphemes: on stem storage}

\subsection{Stem storage avoids conspiratorial zeroes}

Structuralist morphologists conceived of morphemes as atomic Saussurean signs, and of words, phrases, and sentences as combinations of morphemes. These assumptions led to the expectation that morphological segmentation procedures would yield parallel cuts in the form and meaning of complex expressions. A word like men challenged this expectation: its meaning could be decomposed into two elements in the same way as the meaning of regular plural nouns like cat-s and $\operatorname{dog}-s$, but its form appeared to consist of a single piece. A common response to this problem was to analyse men as in fact consisting of two morphs, /men/ and $/ \varnothing /$, where $/ \mathrm{men} /$ was an

2 For an argument against Archangeli \& Pulleyblank's rejection of underlying representations, the reader is referred to Bermúdez-Otero (forthcoming). 
allomorph of the morpheme $\{\operatorname{man}\}$, and $/ \varnothing /$ was an allomorph of the plural morpheme $\{-\mathrm{s}\}$ : see e.g. Bloch (1947). This conspiratorial use of zeroes attracted strong criticism: e.g. Nida (1948: §2.2). As Blevins, Ackerman \& Malouf remind us in this volume, Hockett (1987: 84) came to regard conspiratorial zeroes as the 'reductio ad absurdum' of structuralist morphemics.

Mainstream DM inherits this problem because it treats the plural noun men as a syntactically complex object, but regards the morph $/ \mathrm{men} /$ as the exponent of a single syntactic terminal. First, the plural noun men is assumed to have the following syntactic representation:

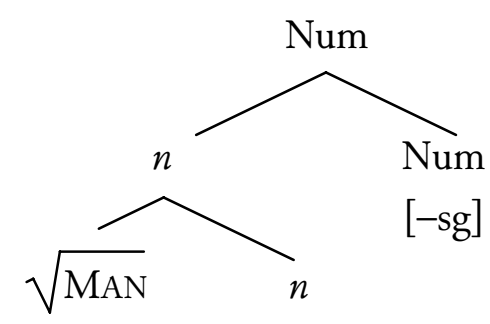

Secondly, vocabulary insertion is assumed to target single syntactic terminals:

(2) Morpheme Insertion Only (Embick forthcoming: §2.1)

The Vocabulary Insertion operation (VI) applies only to morphemes; it cannot target non-terminal nodes.

In consequence, DM must regard $/ \mathrm{men} /$ as an exponent of the root $\sqrt{\text { MAN }}$. Obviously, the insertion of this exponent must be contextually restricted to plural environments, ${ }^{3}$ but that is not enough: in order to avoid ungrammatical */men-z/, DM must also posit a null realization of plural number in the context of the root $\sqrt{\text { MAN }}$.

$$
\begin{aligned}
& \text { a. } \sqrt{\mathrm{MAN}} \leftrightarrow / \mathrm{men} / / \ldots \mathrm{Num}[-\mathrm{sg}] \\
& \sqrt{\mathrm{MAN}} \leftrightarrow / \mathrm{mæn} / \\
& \text { b. } \quad \operatorname{Num}[-\mathrm{sg}] \leftrightarrow \varnothing / X_{-} \quad \mathrm{X}=\{\sqrt{\mathrm{MAN}}, \sqrt{\text { Mouse }}, \sqrt{\mathrm{FoOT}}, \ldots\} \\
& \text { Num[-sg] } \leftrightarrow /-z /
\end{aligned}
$$

Like structuralist morphology, DM has attracted strong criticism for its conspiratorial use of zeroes: see e.g. Pullum \& Zwicky (1991: §4) and Stewart \& Stump (2007: 416-417). These objections are echoed several times in this volume: see Blevins, Ackerman \& Malouf (§3.2.2), Haugen \& Siddiqi (§2ff), and Haugen (§3).

\footnotetext{
3 In the standard analysis, $/ \mathrm{m} \varepsilon \mathrm{n} /$ is not treated as a separate vocabulary item, but is rather derived from $/ \mathrm{m} x$ n/ through the application of a readjustment rule. Here I set this claim aside, since it makes no difference to the problem of conspiratorial zeroes. For arguments against readjustment rules, see Haugen (this volume) and the references therein.
} 
It is nonetheless possible to maintain that the plural noun men is a syntactically complex object but to deny that the morph $/ \mathrm{men} /$ realizes a single syntactic terminal in its structure. Svenonius's (2012, this volume) theory of spanning implements this possibility whilst otherwise sharing several major assumptions about syntax and about morphology with mainstream DM (e.g. phase-theoretic cycles, late insertion, etc). ${ }^{4}$ In this volume, Svenonius suggests that spanning can illuminate one of the central problems for the theory of grammar: the nature of the grammatical word. ${ }^{5}$ Svenonius's version of spanning proceeds in two steps in order to preserve strict modularity (see Bye \& Svenonius 2012). In contrast, Haugen \& Siddiqi (this volume) propose a different implementation, in which vocabulary insertion takes place in a single step after linearization, and they suggest that their version of spanning has applications to the problem of bracketing paradoxes. In the current context, however, these differences can be safely set aside: the key point is that the insertion of a single morph into multiple syntactic terminals, in any of these versions, avoids the problem of conspiratorial zeroes. To see this, consider the vocabulary items listed in (4).
a. $/ \mathrm{men} / \leftrightarrow \sqrt{\mathrm{MAN}} n \operatorname{Num}[-\mathrm{sg}]$
b. $/ \mathrm{mæn} / \leftrightarrow \sqrt{\mathrm{MAN}}$
c. $/-\mathrm{z} / \leftrightarrow \operatorname{Num}[-\mathrm{sg}]$

If realizations involving fewer exponents are preferred, as per Siddiqi's (2009: 4) MinIMIZE EXPONENCE principle, ${ }^{6}$ then /men/ will beat both */mæn-z/ and */men-z/ without the intervention of a contextually restricted zero plural marker. ${ }^{7}$

Bermúdez-Otero's (2013a: 51ff) theory of stem storage yields essentially the same results. The theory differs from spanning models in that it is designed to run in tandem with a rather different framework for word syntax (e.g. Ackema \& Neeleman 2004). In this framework, the problematic containment predictions diagnosed by Embick (forthcoming) and discussed by Haugen \& Siddiqi (this volume: §5) generally do not arise (cf. Caha 2009, Radkevich 2010). As a result, it becomes possible to assert that a single morph can realize an entire word-syntactic treelet.

\footnotetext{
4 Wescoat (2002) develops an articulated theory of multiple-terminal insertion within a lexicalist architecture.

5 Svenonius (this volume: §1) asserts that 'the word is central to lexicalist models, but those models have not developed any theory explaining why words have the boundaries that they do'. This is a largely fair complaint, though see Kiparsky (forthcoming) for criticism of DM's own approach to words (cf. Arregi \& Nevins 2012). My own hunch is that a proper understanding of diachronic pathways of change like grammaticalization and the life cycle of phonological processes (Bermúdez-Otero \& Trousdale 2012) will play a major role in the theory that Svenonius asks for, in line with the Amphichronic Programme (Kiparsky 2006, Bermúdez-Otero 2015, Haugen in this volume).

6 Kiparsky's (2005a: 114) ECONOMY and EXPRESSIVENESS constraints embody a similar idea.

7 Bobaljik \& Wurmbrand (2013) adopt a hybrid model that incorporates a limited amount of multiple-terminal insertion whilst still retaining contextually restricted vocabulary items like (3.a). In contrast, Haugen \& Siddiqi's thoroughgoing implementation of spanning in this volume dispenses with contextual licensing.
} 
In Bermúdez-Otero's model of stem storage, therefore, the noun men is assigned the following lexical entry:

$$
\left[\begin{array}{ll}
\cdots & \\
\ldots 85 & \mathrm{~N}^{-1} \\
\text { SYN } & \mathrm{N}^{0}[\mathrm{pl}] \alpha \\
\text { PHON } & / \mathrm{men} / \alpha
\end{array}\right]
$$

This entry works like an interface rule in the sense of Jackendoff (2002: 131). Postsubscripted Greek letters represent the relationships of exponence holding between elements in the syntactic (SYN) and phonological (PHON) attributes of the noun. ${ }^{8}$ The SYN attribute consists of a wordsyntactic treelet, but this whole complex object is realized by a single morph under the PHON attribute. Thus, mutatis mutandis, lexical entries like (5) capture the same exponence relationships as vocabulary items like (4.a), and their deployment is subject to MINIMIZE EXPONENCE in the same way. In what follows, therefore, I shall treat spanning and stem storage as equivalent for the purposes of the morphology-phonology interface.

As Haugen (this volume) correctly observes, the proponents of mainstream DM may respond that the argument from conspiratorial zeroes appeals to judgements of elegance and that only empirical falsification can settle the matter conclusively. This would be a fair objection: Bermúdez-Otero (2015: 399) issues a similar warning against the abuse of Ockham's razor. In the following sections, therefore, I take the debate to an arena of central concern to DM: locality conditions on allomorph selection.

\subsection{Stem storage widens cyclic domains for allomorph selection just enough}

In this section I use evidence from Spanish third-conjugation verbs to demonstrate that the hypothesis of stem storage leads to improved predictions about cyclic domains for allomorph selection. Section 2.2.1 shows that the alternation between prethematic high and mid vowels in these verbs involves two different mechanisms of phonologically driven allomorph selection: phonological subcategorization in the morphology, and phonotactic optimization in the phonology. The interaction of these two mechanisms generates a spectacular opacity effect without resort to extrinsic rule ordering. Section 2.2.2 goes on to examine the cyclic domain of the alternation. I first present an analysis couched in terms of Stratal Optimality Theory (Stratal OT: Kiparsky 2000, Bermúdez-Otero 2010). Within this framework, the hypothesis of stem storage correctly predicts that the two stems of an alternating third-conjugation verb go through

8 For the sake of simplicity I omit the semantic (SEM) attribute; I also omit information about cyclic domains in the PHON attribute. The arbitrarily chosen number 785 is an index identifying the lexical entry. 
the first cycle of the stem-level phonology separately before competing in the presence of affixal material in the second cycle. In contrast, a DM analysis with single-terminal insertion incurs the problem of the missing cycle as diagnosed by Bermúdez-Otero (2013a: 65ff). To avoid this outcome, Embick (2012) suggests that the alternation should be seen as driven by a word-level morphophonological rule exempt from morphological locality. This proposal incurs serious conceptual problems and relaxes inward cyclic locality far more than the empirical evidence warrants.

\subsubsection{Spanish third-conjugation verbs: subcategorization and phonotactic optimization}

Bermúdez-Otero (2013a: §3) studied the cyclic domains of the Spanish diphthongal alternation: e.g. [kont-á-c] 'count.INF' [kwént-a] 'count.3SG.PRS.IND'. Embick (2012) presents alternative proposals addressing this phenomenon, as well as the alternation between prethematic $[\mathrm{i}, \mathrm{u}]$ and $[e, o]$ that affects an arbitrary subset of Spanish third-conjugations verbs. In this section I deal with the latter, illustrated in (6.a). ${ }^{9}$

1PL.PRS.SBJV

piróá-mos

durm-á-mos

b. nonalternating

$\begin{array}{ll}\text { pedir } & \text { 'ask for' } \\ \text { dormir } & \text { 'sleep' }\end{array}$

$\begin{array}{ll}\text { vivir } & \text { 'live' } \\ \text { divergir } & \text { 'diverge' } \\ \text { fundir } & \text { 'melt' }\end{array}$

biß-á-mos

dißerx-á-mos

fund-á-mos
1PL.PRS.IND

peð-í-mos

dorm-1́-mos

biß-í-mos

dißerx-í-mos

fund-í-mos

This will henceforth be referred to as 'the third-conjugation alternation' or 'the prethematic high $\sim$ mid alternation'.

As is well-known, Spanish verbs fall into three inflectional classes, each characterized by its own theme vowel. The first conjugation, distinguished by thematic $/-\mathrm{a}-/$, is the default and by far the largest: e.g. [kant-á-r] 'sing-TH-INF'. The second conjugation, with thematic/-e-/, and the third conjugation, with thematic /-i-/, are smaller and effectively closed: e.g. [be $\beta$-é-r] 'drink-THINF', [bi $\beta$-i-c] 'live-TH-INF'. The characteristic theme vowel of each class surfaces unchanged in the infinitive, as shown by the previous examples, and in many other derivational and inflectional forms. It is, however, overwritten in certain inflectional (Roca 2010) and derivational contexts: e.g. [beß-e-ðór] 'drinker' [be $\beta$-í- $\beta 1$-e] 'drinkable' (Bermúdez-Otero 2012: 9-14).

In parallel, several alternations target the prethematic vowel: i.e. the vowel in the syllable immediately preceding the thematic element, normally the last vowel of the root. These notably

\footnotetext{
9 My discussion of the Spanish data follows the notational conventions set out in Bermúdez-Otero (2013a: 7, note 4), with the exception that here I do not mark null realizations of the theme position in ordinary $e$-stem nouns and adjectives.
} 
include the diphthongal alternation analysed in Bermúdez-Otero (2013a: §3) and the thirdconjugation high $\sim$ mid alternation presented in (6.a). The diphthongal alternation affects the prethematic vowel in an arbitrary set of verbs belonging to all three conjugations: in their inflectional paradigms, these verbs display prethematic [jé, wé] in rhyzotonic forms (e.g. [kwént-a] 'count.3SG.PRS.IND') and prethematic [e, o] in arhyzotonic forms (e.g. [kont-á- $r$ ] 'count.INF'). Among third-conjugation verbs, the diphthongal alternation and the prethematic high mid alternation can occur either separately or simultaneously:

$$
\text { 1PL.PRS.SBJV 1PL.PRS.IND 3SG.PRS.IND } \begin{aligned}
& \text { high } \sim \text { mid } \\
& \text { alternation? }
\end{aligned} \quad \begin{aligned}
& \text { diphthongal } \\
& \text { alternation? }
\end{aligned}
$$

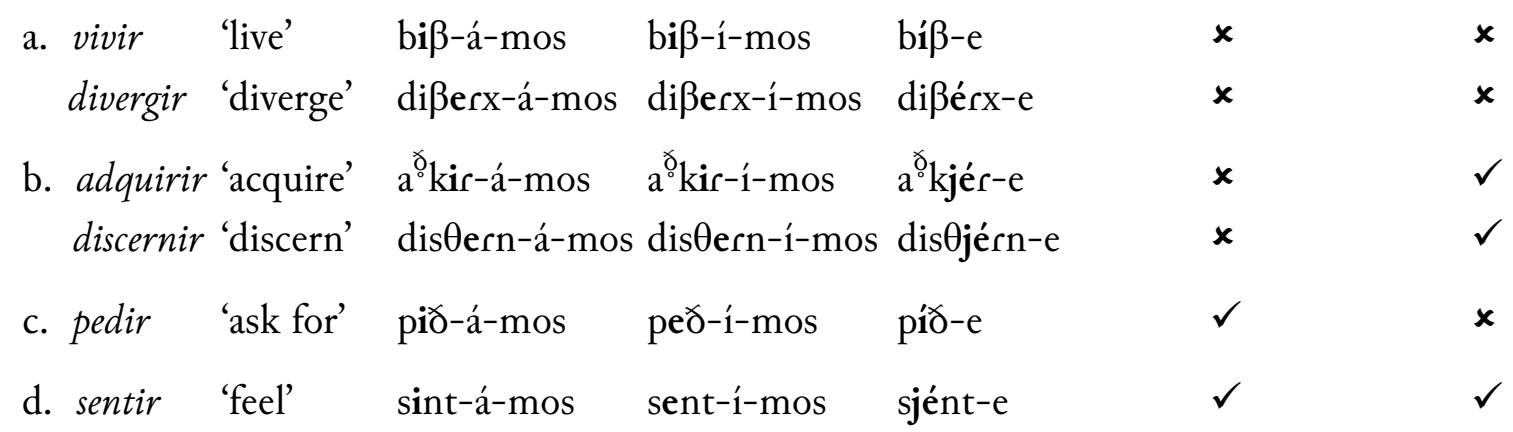

In this section we shall be focusing mainly on the prethematic high $\sim$ mid alternation. For this reason, I shall generally conflate the four verb types in (7) into just two: (7.a) and (7.b) will count as nonalternating verbs for the relevant purposes, (7.c) and (7.d) as alternating.

Let us now turn to the details of the prethematic high mid alternation. ${ }^{10}$ Prethematic $/-a-/$ is found in both marked conjugations (e.g. [lam-é-r] 'lick.INF', [part-í-r] 'part.INF') and does not alternate. In contrast, prethematic high and mid vowels exhibit an intricate distribution reflecting two interacting patterns. The first pattern arises from a pair of height-harmonic subcategorization restrictions which categorically ban the attachment of thematic/-e-/ to a root with final $/ \mathrm{i} /$ or $/ \mathrm{u} /$ and strongly disfavour the attachment of thematic/-i-/ to a root with final /e/ or $/ \mathrm{o} /$. The second pattern is driven by a dissimilatory phonotactic constraint, which penalizes prethematic high vowels when the immediately following syllable is headed by [i].

First, prethematic high vowels are categorically forbidden in verbs of the second conjugation, i.e. in verbs with thematic /-e-/ (Boyé \& Cabredo Hofherr 2004: 252-253). Thus, the language does not tolerate verbs like *[tim-é-r] (cf. [tem-é-r] 'fear.INF') or *[kum-é-r] (cf. [kom-é-r] 'eat.INF'). I analyse this height-harmonic pattern as an inviolable subcategorization restriction, formalized in (8), which prevents underlying /-e-/ from realizing the TH position of a verb stem when the prethematic vowel is high. Since stems are stored anyway, this filter functions

\footnotetext{
10 My understanding of the facts has been crucially informed by the indispensable work of Boyé \& Cabredo Hofherr (2004), even if my analysis diverges from theirs. Boyé and Cabredo Hofherr document key generalizations omitted from Harris's (1969: 104-116) still influential SPE-style account.
} 
in (8): this is shown in (10). For the contrast between violable and inviolable redundancy statements, see Bermúdez-Otero (2012: 19, 32; 2013a: 54-55). ${ }^{11}$

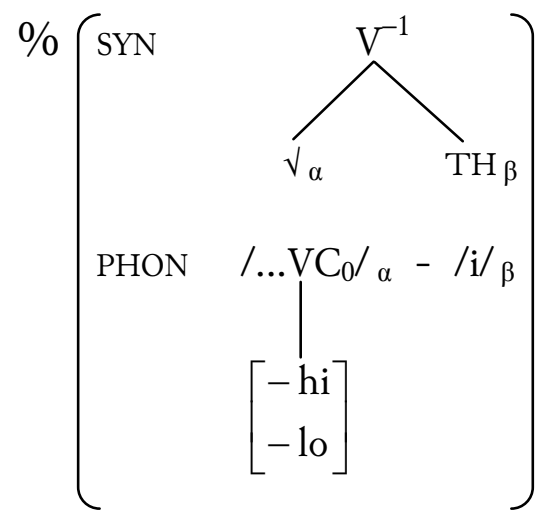

The figures in (9) are drawn from Boyé \& Cabredo Hofherr (2004: 252), who analysed a list of 1,176 verb lexemes of the marked conjugations (including $601 i$-class verbs), ${ }^{12}$ drawn from an exhaustive lexicographic corpus of over 11,095 Spanish verbs. Their numbers show that the prethematic high $\sim$ mid alternation is far from pervasive: it affects only $24 \%$ of verb lexemes in the third conjugation, and just $1 \%$ of all verb lexemes. Thus, alternating verbs form a minority set whose membership is strictly unpredictable. We must therefore infer that participation in the prethematic high mid alternation is determined lexically, rather than phonologically. In a framework with stem storage, this suggests that a verb like pedir (7.c) has two listed stems: /v pid-i/ and /V ped-i/. Gratifyingly, this conclusion is supported by psycholinguistic and neurolinguistic data.

Linares, Rodriguez-Fornells \& Clahsen (2006) performed a wug test eliciting forms of nonce third-conjugation verbs rhyming with existing alternating verbs: e.g. nonce ${ }^{\varnothing}$ redir, which rhymes with the actual verb pedir (7.c). ${ }^{13}$ When the experimental stimuli provided direct and unambiguous evidence of participation in the third-conjugation alternation (i.e. one sentence containing < redir> INF, the next sentence containing < rido> 1SG.PRS.IND), participants produced alternating responses (i.e. 3PL.PRS.IND <riden>) $79 \%$ of the time. But when the nonce verb was presented in the infinitive only (i.e. <redir>, no 1SG.PRS.IND stimulus), the number of alternating responses fell to $25 \%$, of which $6 \%$ followed the diphthongal alternation (i.e. 3PL.PRS.IND $<$ rieden>) like sentir (7.d) and 19\% followed the prethematic high $\sim$ mid alternation (i.e.

11 The key idea is that the contrast between violable and inviolable redundancy statements can easily be modelled by means of constraint interaction. If (8) and (10) are turned into optimality-theoretic constraints (see e.g. Trommer 2001), then (8) will be ranked above faithfulness to individual stem entries, and (10) will be ranked below. In that case, (10) will constitute a close morphological analogue of Zuraw's (2010) 'subterranean constraints' in phonology: see Bermúdez-Otero (2012: 32, 39) for discussion of the latter.

12 This set of 601 third-conjugation verbs results from adding highly irregular ir 'go' plus 57 items with prethematic /a/ to the 543 verbs with prethematic high, high mid, and mid vowels in (9) above.

13 The superscript ${ }^{\varnothing}$ denotes a lexical gap, i.e. a well-formed but nonexistent lexical item. 
3PL.PRS.IND <riden>) like pedir (7.c). In this condition, therefore, participants strongly preferred to inflect ${ }^{\varnothing}$ redir like completely nonalternating divergir (7.a), even though, according to Boyé \& Cabredo Hofherr's (2004: 252) figures, only 3\% of verbs with prethematic mid vowels in the $i$-class participate neither in the high $\sim$ mid nor in the diphthongal alternation. In a refined dualroute model of morphology (Bermúdez-Otero 2012: 40-44, and references therein), therefore, the clear minority of alternating responses in the single-stimulus condition is best interpreted as driven by family resemblance with existing stored stems, rather than by the application of a grammatical rule.

In a second experiment, Linares, Rodriguez-Fornells \& Clahsen (2006) exposed native speakers of Spanish to orthographic tokens of incorrect 3PL.PRS.IND forms of existing alternating $i$-class verbs like pedir. One set of incorrect forms contained the wrong prethematic vowel: e.g. ${ }^{*}<$ peden $>$ for $<$ piden $>$. Another set consisted of forms containing the wrong agreement suffix: e.g. $<$ pides $>$ 2SG.PRS.IND in a context demanding < piden $>$ 3PL.PRS.IND. Analysis of the event-related potentials (ERPs) evoked by these stimuli revealed that incorrect prethematic vowels triggered an attenuated N400, whereas incorrect agreement markers triggered an enhanced P600. Although neurolinguists do not agree on the functional significance of the N400 response, this finding is consistent with an analysis in which the ERP modulations caused by incorrect prethematic vowels reflected lexical access effects, whereas those caused by incorrect agreement markers reflected a combinatorial violation.

In sum, Linares, Rodriguez-Fornells \& Clahsen's findings make it possible to determine the productivity of the prethematic high $\sim$ mid alternation and its cognitive basis very precisely. Their elicitation experiments show that, when presented with positive evidence of alternating behaviour, native speakers of Spanish are capable of learning new third-conjugation verbs of the pedir type and distribute their allomorphs in the expected way in production. ${ }^{14}$ In the absence of such positive evidence, however, Spanish speakers rarely generalize the alternation to wug items, even when this entails assigning novel verbs to the vanishingly small divergir type-but recall that, as Boyé \& Cabredo Hofherr (2004: 252) show, the pedir type itself forms a clear minority (less than one fourth) of the $i$-class, most of whose members (over two thirds) behave like nonalternating vivir (7.a). These results confirm our hypothesis that participation in the thirdconjugation alternation is a matter of storage, whereas the distribution of the two stored allomorphs, when they happen to exist, is controlled by the computation. Linares, Rodriguez-

\footnotetext{
14 One must attach an important caveat to this statement. Patricia Cabredo Hofherr (personal communication) reports that, in wug tests designed to elicit second- or third-conjugation verbforms, she involuntarily and automatically reassigns the novel lexeme to the unmarked first conjugation, even though this results in a paradigmatic mismatch with the wug stimulus. In this type of response, for example, an informant probed for the 1PL.PRS.IND form of the third-conjugation wug item ${ }^{\varnothing}$ redir INF produces first-conjugation ${ }^{\varnothing}$ redamos, instead of third-conjugation

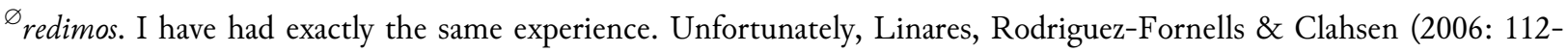
113) do not report the proportion of conjugation-inappropriate responses in their elicitation experiment. Nonetheless, their results suggest that learning of new alternating verbs of the third conjugation should indeed be possible under naturalistic conditions, given sufficient exposure.
} 
Fornells \& Clahsen's ERP data agree perfectly with this interpretation. I therefore conclude that, as anticipated above, alternating $i$-class verbs like pedir possess two listed stems: /v pid-i/ and /v ped-i/.

Although the existence of two allomorphs is an arbitrary lexical fact, their distribution is phonologically predictable and, as shown by Linares, Rodriguez-Fornells \& Clahsen's behavioural data, synchronically productive. The mid-vowelled stem is selected whenever the syllable immediately following the prethematic vowel has [i] as its designated terminal element; if the syllable immediately following the prethematic vowel is headed by any other vowel, the highvowelled stem is chosen. In the case of pedir, therefore, /v ped-i/ occurs if, on the surface, the final [d] of the root immediately precedes syllable-heading [i], whereas /V pid-i/ prevails if, on the surface, [d] immediately precedes any other vocoid, including the onglide [j]. This dissimilatory pattern is completely transparent and strictly exceptionless. In (11) I illustrate it with a fragment of the inflectional paradigm of pedir; the relevant syllable heads are highlighted in boldface. Contrasts of interest include prethematic [e] in the 1PL.PRS.IND vs prethematic [i] in the 1PL.PRS.SBJV, prethematic [e] throughout the IPFV.IND vs prethematic [i] throughout the IPFV.SBJV, and prethematic [e] in the 1SG.PRET vs prethematic [i] in the 3SG.PRET.

$\begin{array}{llllll} & \text { PRS.IND } & \text { PRS.SBJV } & \text { IPFV.IND } & \text { IPFV.SBJV } & \text { PRET } \\ \text { 1SG } & \text { píðo } & \text { píða } & \text { peðía } & \text { piðjése } & \text { peðí } \\ \text { 2SG } & \text { píðes } & \text { píðas } & \text { peðías } & \text { piðjéses } & \text { peðíste } \\ \text { 3SG } & \text { píðe } & \text { píða } & \text { peðía } & \text { piðjése } & \text { piðjó } \\ \text { 1PL } & \text { peðímos } & \text { piðámos } & \text { peðíamos } & \text { piðjésemos } & \text { peðímos } \\ \text { 2PL } & \text { peðís } & \text { piðð́js } & \text { peðíamos } & \text { piðjésemos } & \text { peðímos } \\ \text { 3PL } & \text { píðen } & \text { píðan } & \text { peðían } & \text { piðjésen } & \text { piðjéron }\end{array}$

Whilst the data in (11) have been endlessly repeated, it is less often noticed that this pattern of phonologically conditioned allomorph selection generalizes with complete regularity across deverbal derivation too, as shown in (12).
$(12)^{15}$
UR
a. $\quad\left[\mathrm{N}\left[\mathrm{V}\left\{\begin{array}{l}\text { pid-i } \\ \text { ped-i }\end{array}\right\}\right] \mathrm{dor}\right.$
SR
b. $\quad\left[\right.$ A $\left[\right.$ v $\left.\left\{\begin{array}{l}\text { pid-i } \\ \text { ped-i }\end{array}\right\}\right]$ bl-e $] \quad$ peðíkle 'which may be asked for'

\footnotetext{
15 For the sake of clarity, I omit the underlying allomorphy of the theme vowel of ordinary $e$-stem nouns and adjectives (Bermúdez-Otero 2013a: 10ff). I also set aside the analysis of the allomorphy that the derivational suffixes $-b l-e$ and $-n t-e$ cause in the theme vowel of the base verb (Bermúdez-Otero 2012: 9-14).
} 

c. $\quad\left[\mathrm{A}\left[\mathrm{V}\left\{\begin{array}{l}\text { pid-i } \\ \text { ped-i }\end{array}\right\}\right]\right.$ nt-e $] \quad$ piðjénte 'who asks for something'
d. $\quad\left[\mathrm{N}\left[\mathrm{v}\left\{\begin{array}{l}\text { pid-i } \\ \text { ped-i }\end{array}\right\}\right]\right.$ on $\rrbracket \quad$ piðón 'one who asks for things importunately'

Several diagnostics confirm that these derivatives are deverbal, and not deradical (Bermúdez-Otero 2013a: 23-26, 34-38). Semantically, they are all perfectly compositional. In (12.a) and (12.b), moreover, the theme vowel of the verb stem surfaces unchanged inside a consonant-initial suffix. In (12.c), the theme vowel of the verb surfaces too, though with idiosyncratic allomorphy induced by the suffix. In (12.d), the theme vowel of the verb is present underlyingly, but is deleted by a completely general phonological process that applies across all lexical categories (Bermúdez-Otero 2013a: 33-50). In turn, the suffixes themselves are all stem-level, as independently shown by their behaviour with respect to the diphthongal alternation (Bermúdez-Otero 2013a: 23-24, 36-37, $72 \mathrm{ff}$ ). The choice of prethematic vowel in the base stem is thus determined by the quality of the vowel heading the following syllable in the output of the stem-level phonology, and this choice remains transparent on the surface.

The data in (11) and (12) reveal a canonical case of allomorph selection by phonotactic optimization. The allomorphs themselves are listed, but their pattern of distribution bears all the hallmarks of genuine phonological computation:

- it is phonotactically conditioned (dissimilatory);

- it does not hold over underlying representations, where subcategorization instead favours height-harmonic stems like /V beb-e/ 'drink' (8) and /V bib-i/ 'live' (10);

- it is sensitive to phonologically derived properties which are present in the output of the stem level but not underlyingly;

and - it remains transparent on the surface.

For the sake of argument, I shall assume that the constraint driving dissimilation is a member of the OCP family, which I shall label $\mathrm{OCP}\left(\mathrm{V}^{[+h i]} \cdot \mathrm{C}_{0} \mathrm{i}\right)$. The constraint $\mathrm{OCP}\left(\mathrm{V}^{[+h i]} \cdot \mathrm{C}_{0} \mathrm{i}\right)$ must be ranked below IDENT-[hi], since in the absence of an allomorphic choice Spanish tolerates [...iC $\mathrm{i}_{1}$ i...] sequences: e.g. [míli] 'military service'. In addition, I assume that prethematic /i/ prevails when it is not followed by a dissimilation trigger because corner vowels are unmarked relative to mid vowels. 
(13)

\begin{tabular}{|c|c|c|c|c|c|c|c|}
\hline & & & $S \mathcal{L}$ & 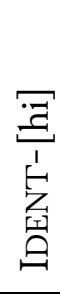 & 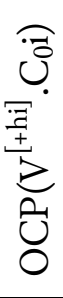 & $\begin{array}{l}\overline{0} \\
1 \\
-\overrightarrow{1} \\
\frac{1}{*}\end{array}$ & $\frac{ت}{\stackrel{\Xi}{ \pm}}$ \\
\hline \multirow{2}{*}{\multicolumn{2}{|c|}{ mili }} & mí.li & 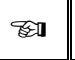 & & $*$ & & $* *$ \\
\hline & & mé.li & & $* !$ & & $*$ & $*$ \\
\hline $\multirow{4}{*}{\begin{array}{l}\text { pí.di } \\
\text { pé.di }\end{array}}-$ dor & \multirow{2}{*}{ pí.di - dor } & pi.di.dór & & & $* !$ & $(*)$ & $*(*)$ \\
\hline & & pe.di.dór & & $* !$ & & $*(*)$ & $(*)$ \\
\hline & \multirow{2}{*}{ pé.di-dor } & pi.di.dór & & $* !$ & $*$ & $(*)$ & $*(*)$ \\
\hline & & pe.di.dós & 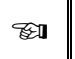 & & & $*(*)$ & $(*)$ \\
\hline \multirow{4}{*}{$\begin{array}{l}\text { pí.di } \\
\text { pé.di }\end{array}$} & \multirow{2}{*}{ pí.di - on } & pi.dón & 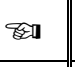 & & & $(*)$ & \\
\hline & & pe.dón & & $* !$ & & $*(*)$ & \\
\hline & \multirow{2}{*}{ pé.di - on } & pi.dón & & $* !$ & & $(*)$ & \\
\hline & & pe.dón & & & & $* !(*)$ & \\
\hline
\end{tabular}

Observe that the markedness hierarchy $*[-\mathrm{hi},-\mathrm{lo}] \gg *[+$ hi $]$ is perfectly compatible with the fact that Spanish uses [e] as the default vowel in cases of epenthesis. The latter reflects the ranking of DEP constraints (Staroverov 2014: 206):

\begin{tabular}{|c|c|c|c|c|c|c|}
\hline & $S \mathcal{L}$ & 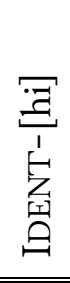 & 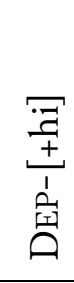 & $\begin{array}{l}0 \\
0 \\
1 \\
-\hat{a} \\
1 \\
1 \\
\text { a1 } \\
0\end{array}$ & $\begin{array}{l}\overline{0} \\
1 \\
. \overrightarrow{1} \\
\frac{1}{*}\end{array}$ & 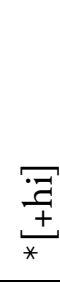 \\
\hline \multirow{2}{*}{ snob } & is.nob & & $* !$ & & $(*)$ & $*$ \\
\hline & es.nob & & & $*$ & $*(*)$ & \\
\hline
\end{tabular}

Spanish verbs of the third conjugation thus offer a striking illustration of the fact that the architecture of grammar provides two separate mechanisms for phonologically conditioned allomorph selection: subcategorization in the morphology and phonotactic optimization in the phonology. The two coexist and interact (Bermúdez-Otero 2012: 51-52, and references therein). The subcategorization restriction in (10) accounts for the extreme rarity of verbs like divergir (7.a) and discernir (7.b) by penalizing stems that combine thematic/-i-/ with a root whose last vowel is mid. This pattern is height-harmonic, holds over underlying representations, and becomes opaque whenever thematic /-i-/ fails to surface as [i]. In contrast, the stem-level phonological constraint hierarchy in (13) accounts for the fact that alternating two-stem verbs like pedir (7.c) exhibit 
prethematic [e] precisely in those forms where thematic /-i-/ surfaces faithfully. This pattern involves height dissimilation, holds over stem-level output representations, and is transparent. The result is a spectacular markedness reversal in the transition from morphology to phonology: subcategorization is height-harmonic, whereas phonotactically driven selection is dissimilatory. This reversal demonstrates that allowing phonological subcategorization to coexist with allomorph selection by phonotactic optimization does not create a duplication problem, pace Bye (2015: 120121) and Paster (2015: 237-240); on the contrary, the two mechanisms complement each other.

The opaque derivation of [piðámos] 'ask_for.1PL.PRS.SBJV' has important theoretical implications too. The prethematic [i] in this form derives from the stem /v pid-i/, whose existence is expected in accordance with the height-harmonic pattern whereby the theme vowel /-i-/ prefers to combine with roots whose last vowel is high; yet the thematic/-i-/ that drives phonological subcategorization in the stem /V pid-i/fails to surface in the wordform [piðámos]. Further to obscure the pattern, the forms of pedir in which thematic /-i-/ does surface as [i] display prethematic [e], from /V ped-i/, in accordance with a dissimilatory phonotactic preference. Nonetheless, this opacity effect emerges without resort to extrinsic rule ordering; cf. Harris's (1969: 107, 112, 113) SPE-style derivations, with their multiple Duke-of-York gambits. Fully in the spirit of Stratal OT, this result supports Kiparsky's (forthcoming) contention that extrinsically ordered rules are not needed in the morphology, just as they are not needed in the phonology; the modular architecture of the grammar suffices (cf. Arregi \& Nevins 2012).

Finally, observe that my analysis eschews conjugation diacritics: no statement in the grammar resorts to a specification like [Class:III] (cf. Harris 1969: 106, 109). As shown in Bermúdez-Otero (2013a: §2), stem storage removes the need for inflectional class features in Spanish morphology—and possibly more widely, as suggested by Wunderlich (1996: §6).

\subsubsection{Cyclic locality in the Spanish third-conjugation alternation}

We are now ready to address the question of cyclic locality in the Spanish third-conjugation alternation. For the sake of concreteness, I shall compare two approaches: one from Stratal OT with stem storage (Bermúdez-Otero 2013a), and one from mainstream DM (Embick 2012). The comparison will focus specifically on the augmentative agentive noun [piðón] (12.d), in whose derivation Stratal OT and mainstream DM posit the same sequence of cycles: the first over the verb PEDIR, the second over the deverbal noun PIDÓN. The results of this comparison, however, apply more widely to the general debate on single-terminal vs multiple-terminal insertion.

In Stratal OT, root-based stems trigger cycles of the stem-level phonology (BermúdezOtero 2006: 283). In consequence, each of the two stems of the verb PEDIR, namely /v pid-i/ and /v ped-i/, goes through a separate stem-level cycle. In turn, Spanish evaluative suffixes are wordlevel in adnominal category-preserving use, but stem-level when attached to verbs to derive agentive or eventive nominalizations (Bermúdez-Otero 2013a: 24, 36-37). Accordingly, the addition of augmentative -ÓN to PEDIR triggers a second cycle of the stem-level phonology. It is in 
this second cycle of the stem-level phonology that the competition between /v pid-i/ and /v ped-i/ is resolved by phonotactic optimization.

More technically, the fact that the stems /v pid-i/ and /v ped-i/ are subject to phonological selection by phonotactic optimization is recorded in a SUBCAT attribute within their respective lexical entries (Bermúdez-Otero 2013a: 72-73):

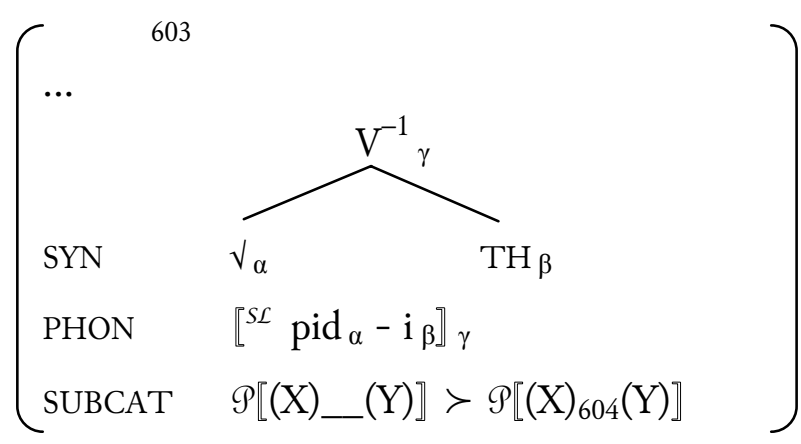

(16)

$$
\left(\begin{array}{ll}
\cdots & \underbrace{604}_{V_{\alpha}} \\
\text { SYN } & \operatorname{TH}_{\beta} \\
\text { PHON } & \left.{ }^{S \mathcal{L}} \operatorname{ped}_{\alpha}-\mathrm{i}_{\beta}\right]_{\gamma} \\
\text { SUBCAT } & \left.\left.\mathcal{P}[\mathrm{X})_{-}(\mathrm{Y})\right] \succ \mathscr{P}(\mathrm{X})_{603}(\mathrm{Y})\right]
\end{array}\right)
$$

Thus, the SUBCAT attribute of / $\mathrm{v}$ pid-i/ in (15) says that the use of this stem is licensed in a given cyclic domain $\left[(\mathrm{X}) \_(\mathrm{Y})\right]$ only if applying the phonological function $\mathscr{P}$ to $[(\mathrm{X})$ pidi $(\mathrm{Y})]$ produces a more harmonic output than doing so to $[(\mathrm{X})$ pedi $(\mathrm{Y})]$, and vice versa. This triggers the computation shown in tableau (13) above. The PHON attributes in (15) and (16) also redundantly record the fact that /V pid-i/ and /v ped-i/ define stem-level domains $\left({ }^{S L}\right)$ by themselves, although, as we have seen, this is independently determined by the theory's principles of cyclic domain assignment. $^{16}$

The derivation of [piðón] therefore proceeds as follows:

16 In fact, the theory of stem-level nonanalytic listing advanced in Bermúdez-Otero (2012: 15-40, 2013b) asserts that the output of the stem-level phonology is also redundantly stored: see section 3 below for an application of this idea. In this view, therefore, the PHON attribute in (15) should in fact appear as follows: $\left.{ }^{S \mathcal{L}} \operatorname{pid}_{\alpha}-\mathrm{i}_{\beta}\right]_{\gamma} \rightarrow$ [pí.di]. 
a. word syntax

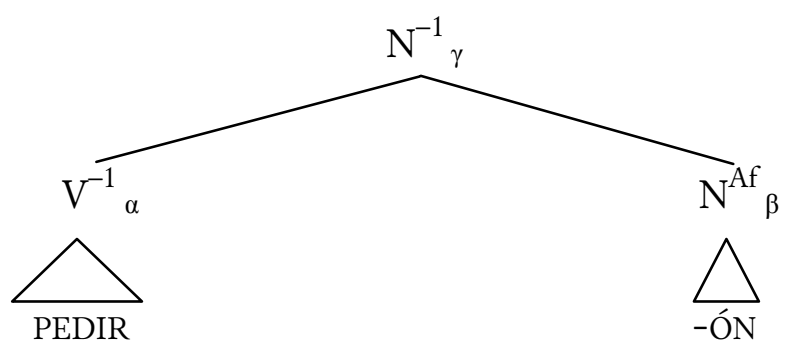

b. underlying phonological representation

$$
\left[S \mathcal{L}\left\{\begin{array}{l}
{\left[{ }^{S \mathcal{L}} \text { pid-i }\right]} \\
{[S \mathcal{L} \text { ped-i }]}
\end{array}\right\}_{\alpha}-{ }^{-o n_{\beta}}\right]_{\gamma}
$$

c. phonological derivation

$$
\begin{array}{lll} 
& \text { input } & \text { output } \\
\text { first cycle }(S \mathcal{L}) & \begin{array}{l}
\text { /pid-i/ } \\
\text { /ped-i/ }
\end{array} & \rightarrow[\text { [pí.di] } \\
\text { second cycle }(S \mathcal{L}) & \left\{\begin{array}{l}
{[\text { pí.di] }] \text {-on }} \\
{[\text { pé.di]-on }}
\end{array}\right\} & \rightarrow \text { [pi.dón] }
\end{array}
$$

The implications for cyclic locality are straightforward. If /pid-/ and /ped-/ were allomorphs of the root $\sqrt{\mathrm{PID}}$, then they would compete in the first cycle of the derivation, triggered by the deradical verb PEDIR; but this cannot be, as selection must take place in a cycle where the /o/ of the augmentative suffix -ón is visible, overwriting the theme vowel of the verb and so blocking the dissimilatory selection of prethematic /e/. In contrast, if /pid-i/ and /ped-i/ are allomorphs of the verb PEDIR, and consequently go through the first cycle of the derivation by themselves, then they will compete in the second cycle, triggered by the deverbal noun PIDón: in this cycle, the /o/ of the augmentative suffix is visible, correctly leading to the selection of /pid-i/. Thus, replacing root storage with stem storage leads to a minimal expansion of the local domain for allomorph selection in the Spanish third-conjugation alternation: it expands from the first to the second cycle (Bermúdez-Otero 2013a: 71). The empirical facts show that this is necessary and sufficient: it is the minimal relaxation of cyclic locality compatible with the data.

Let us now consider the problem from the viewpoint of mainstream DM. In this framework, pidón is analysed as having the structure shown in (18). The two category-giving heads $v$ and $n$ are cyclic, and so spell-out proceeds in two cycles. 
(18)

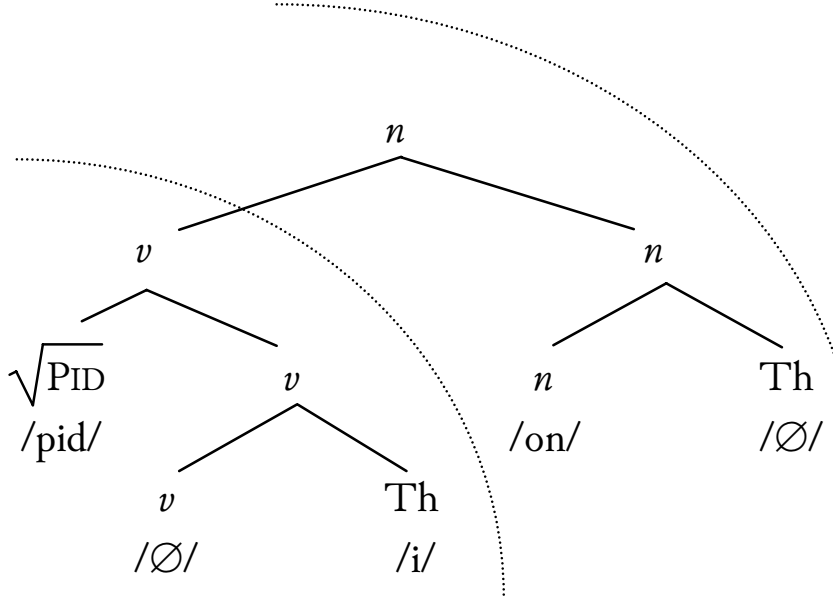

Participation in the third-conjugation alternation, manifested in the contrast between [piðón] and [peðiðór] $(12 . \mathrm{d}, \mathrm{a})$, is seen as a property of the root $\sqrt{\mathrm{PID}}$. To account for the alternation, Embick (2012: 33) therefore proposes the following rule:

$$
\text { Dissimilation: } \mathrm{i} \rightarrow \mathrm{e} / \ldots(\mathrm{C}) \mathrm{i}
$$

$<$ for the specified class of Roots $>$

Now suppose that (19) were a typical readjustment rule, applying early in spell-out after vocabulary insertion. Since /pid/ expones a root included in the list of targets for dissimilation, the conditions for rule (19) are met in the first spell-out cycle, and the /i/ of the root is lowered to /e/. As this /e/ is carried over to the second spell-out cycle, the result is *[peðón]. ${ }^{17}$

$\begin{array}{lll}\text { first cycle: } & \begin{array}{l}\text { insertion } \\ \text { dissimilation }\end{array} & \begin{array}{l}\text { pid-i } \\ \text { pé.di }\end{array} \\ \text { second cycle: } & \text { insertion } & \text { pé.di-on } \\ & \text { truncation } & \text { pe.dón }\end{array}$

A possible solution might be to move rule (19) into the postcyclic (word-level) phonology, despite the misgivings expressed by Haugen (this volume: §3.1) about sprinkling readjustment rules all over the morphology and the phonology. The intention would be to produce the following derivations:

17 [peðón] happens to exist as the pronunciation of 'fart.AUG', not the meaning intended here. 
(21)

$\begin{array}{llll} & & \text { a. } & \text { b. } \\ & & (12 . \mathrm{d}) & (12 . \mathrm{a}) \\ \text { first cycle: } & \text { insertion } & \text { pid-i } & \text { pid-i } \\ \text { second cycle: } & \text { insertion } & \text { pí.di-on } & \text { pí.di-dor } \\ & \text { truncation } & \text { pi.dón } & - \\ \text { postcycle: } & \text { dissimilation } & - & \text { pe.ði.ðór }\end{array}$

Yet this move actually fails to produce the desired effects because the derivation of [peðiðór] in (21.b) violates cyclic locality. By the time the derivation reaches the postcyclic phonology, the morphological affiliation of /pid/ with the root $\sqrt{\mathrm{PID}}$ should no longer be accessible. If so, input /pi.di.dór/ ought to be unable to satisfy the morphological requirements for dissimilation. Indeed, this conception of cyclic locality comports well with the following statement:

(22) Readjustment Activity Hypothesis (Embick 2010: 101)

A readjustment rule triggered by morpheme $X$ can effect a Root- or morpheme specific change only when $X$ and the Root/functional head are in the same PF cycle.

I conclude that, if (19) is a readjustment rule, then the Spanish third-conjugation alternation falsifies the theory of cyclic locality set out in Embick (2010). The theory turns out to be too restrictive.

The question then becomes: can cyclic locality be relaxed to the correct extent whilst retaining the assumption of single-terminal insertion? Embick (2012) suggests that it can. His argument is that the Readjustment Activity Hypothesis does not apply to rule (19) because this rule is not in fact a readjustment; rather, dissimilation is a postcyclic morphologically conditioned phonological rule and so is exempt from morphological locality restrictions like (22), but is rather subject only to phonological locality (see also Embick 2014). The property which allegedly distinguishes (19) from a true readjustment rule like (23) is the fact that, although the target of (19) bears a morphological specification, the trigger does not.

$$
\begin{aligned}
& / \mathrm{I} / \rightarrow \mid \mathfrak{x} / / \mathrm{X} \_ \text {_ }[\text { [past] } \\
& \quad \mathrm{X}=\sqrt{\operatorname{SinG}}, \sqrt{\mathrm{RING}}, \sqrt{\operatorname{SinK}}, \sqrt{\mathrm{BEGIN}}, \sqrt{\operatorname{SiT}}, \ldots
\end{aligned}
$$

However, we should reject Embick's (2012, 2014) solution for conceptual and empirical reasons. First, his proposal distorts the concept of phonological locality beyond recognition. According to the usual understanding of this idea, a phonological process of the generic form $\mathrm{A} \rightarrow \mathrm{B} / \mathrm{C} \_\mathrm{D}$, where $\mathrm{A}, \mathrm{B}, \mathrm{C}$, and $\mathrm{D}$ are phonological objects, may apply only if the target CAD meets the appropriate requirements of linear adjacency and prosodic containment. Kiparsky (1994) 
was the first to propose that morphophonological rules can be distinguished from suppletive allomorphy by the fact that the former obey phonological locality. In Present-day German, for example, the morphologically restricted phonological process of umlaut fails to apply in Monat 'month' *Mönat-chen 'month-DIM' (Fanselow \& Féry 2002: 266, 276-277) because, although the suffix - chen is morphologically adjacent to the stem Monat-, the mutation trigger (presumably a floating [-back] autosegment associated with -chen) is not phonologically local to the target vowel /o:/. In this light, an appropriate interpretation of Kiparsky's (1994) proposal is that satisfaction of the morphological conditions on a morphophonological rule is bound by morphological locality, whereas satisfaction of its phonological conditions is bound by phonological locality. ${ }^{18}$ Embick (2012, 2014) makes a radically different claim: namely, that postcyclic morphophonological rules, being exempt from morphological locality, can access all the morphological properties of the material in their scope. This suggestion produces counterintuitive and paradoxical results. It entails that, in the derivation of Spanish [peðiðóc] in (21.b), the relationship of exponence between $\sqrt{\mathrm{PID}}$ and /pid/ ceases to be visible to the morphology in the second spell-out cycle, but remains visible to the phonology in the word-level stratum. Thus, the postcyclic phonology enjoys greater and deeper access to morphological information than morphology does itself.

More decisively, Embick's $(2012,2014)$ hypothesis relaxes cyclic locality far more than the empirical facts of the Spanish third conjugation warrant. Recall, first, that we have powerful reasons for regarding membership in the alternating set as an idiosyncratic allomorphic property of individual lexemes like PEDIR: the alternation does not apply to all lexical categories, but only to verbs; within verbs, it does not apply to all classes, but only to the smallest conjugation, which is effectively closed; within the third conjugation, it does not apply to the majority of verbs, but rather to fewer than one fourth (Boyé \& Cabredo Hofherr 2004). Moreover, native speakers refrain from extending the alternation to novel items, unless directly presented with positive evidence of alternating behaviour (Linares, Rodriguez-Fornells \& Clahsen 2006). Yet Embick's analysis entails that this eminently idiosyncratic allomorphic property remains visible to the postcyclic phonology regardless of how deeply embedded PEDIR is within the structure. We may bury PEDIR under an arbitrarily large number of category-determining affixes; ${ }^{19}$ still, Embick's prediction is that the root $\sqrt{\text { PID }}$ remains visible to the postcyclic phonology, and apt to flip from /pid/ to /ped/ in response to a phonological contingency arising during the $n^{\text {th }}$ round of categorydetermining derivation. This goes far beyond what the Spanish data call for. As we saw above, the

18 In this vein, Bermúdez-Otero (2012: 44, 81-82) asserts explicitly that access to morphosyntactic information in phonology is restricted by both inward and outward cyclic locality. He argues that, in Stratal OT, this need not be stated as a separate axiom, but follows as a theorem from independently motivated principles. This result preserves the insight behind Orgun and Inkelas's (2002: 126) Relativized Opacity Theorem, which encodes a carefully nuanced version of inward cyclic locality.

19 For example, starting with pedir 'ask for', we may first add -nt-e to form the agentive nominal pidiente 'who asks for something' (attested), then -er-o to form the occupational nominal pidientero 'mendicant' (attested), then -ism-o to form the abstract noun ${ }^{\varnothing}$ pidienterismo 'mendicancy' (not attested but perfectly well-formed), and so on and so forth. 
evidence is consistent with the much more restrictive prediction made by Stratal OT with stem storage: the local domain for allomorph selection in the Spanish third-conjugation alternation is the second cycle, not the entire word. ${ }^{20}$ Significantly, the permissiveness of Embick's $(2012,2014)$ strategy brings mainstream DM closer to noncyclic OT than may appear at first blush. Since Embick's (2010) critique of the unrestricted globalism of noncyclic OT was in fact well-taken, such an enfeeblement of cyclic locality would be disappointing and should be resisted.

In this section, I have shown that it is indeed possible to uphold a far stronger theory of cyclic locality in allomorph selection. The key is to abandon the assumption of single-terminal insertion, as argued on independent grounds by Svenonius (2012) and Merchant (2015), and in this volume by Haugen \& Siddiqi, Haugen, and Svenonius.

\subsection{Stem storage maintains parallel cycles of phonological and semantic interpretation}

The failed derivation in (20) illustrates a general problem for mainstream DM, arising from its inability to handle situations in which allomorphy inheres in categorized lexical items such as Spanish third-conjugation verbs, rather than in acategorial roots or in functional heads. The hypothesis of insertion into single terminals allows vocabulary items and readjustment rules to be associated with simple roots, but not with complexes consisting of a root plus a category-giving head. Accordingly, if a lexical item exhibits allomorphy, this must be a property of its root, and exponent selection must therefore take place in the first cycle of the derivation, during which the root is spelled out alongside $v, n$, or $a$. As (20) shows, however, Spanish $i$-class verbs and their derivatives fail to exhibit the expected allomorphic effects of the first spell-out cycle, precisely because the prethematic high mid alternation is not a property of roots, but of lexemes (in DM terms, of $\sqrt{ } v$ complexes). Bermúdez-Otero (2013a: 65ff) called this 'the problem of the missing cycle' and showed that it is also raised by the Spanish diphthongal alternation.

As we saw in the previous section, Embick's $(2012,2014)$ response is to exempt word-level morphophonological processes from inward cyclic locality restrictions on access to morphological information, thereby reducing the distance between his theory and mainstream OT (e.g. Pater 2009; cf. Bermúdez-Otero 2012: 66-67). In this section I examine the alternative strategy pursued by Myler (2015): his solution to the problem of the missing cycle in Spanish is to assert that stemlevel phonological rules do not apply in spell-out cycles triggered by verb stems. In section 2.3.1 I show that this proposal fails for empirical reasons: it relies on incorrect claims about the cyclic transmission of stress-induced hiatus in Spanish denominal derivation, and it overgenerates hiatus in inflected verbs and deverbal derivatives. In section 2.3.2 I argue that Myler's strategy should be rejected for conceptual reasons too: solutions of this type, also adopted by Marantz (2013: 114) and Embick (2014), amount to an unprincipled retreat from the fundamental idea that word

20 See Bermúdez-Otero (2013a: 68, footnote 48) for an analogous observation about the diphthongal alternation. 
formation involves parallel cycles of morphophonological and semantic interpretation (cf. Marvin 2002: 31-32, Marantz 2007: §1).

\subsubsection{The cyclic transmission of stress-induced hiatus in Spanish denominal derivatives}

Myler's (2015) response to the problem of the missing cycle in Spanish is to take it at face value: his contention is that the first cycle of derivations like (20) fails to produce the expected morphophonological effects simply because the phonology is turned off during that cycle. In more technical terms, he stipulates that, in Spanish, the rules of the cyclic phonology apply during a spell-out cycle only if the cyclic domain is headed by $n$ or $a$, but not if it is headed by $v$. Myler's proposal, designed to deal with the diphthongal alternation, dispatches the difficulties raised by the third-conjugation alternation too: derivation (20) is replaced with (24).

$\begin{array}{llll}\text { first cycle (domain beaded by } \mathrm{v}): & \begin{array}{l}\text { insertion } \\ \text { dissimilation }\end{array} & - & \text { (no phonology in this cycle) } \\ \text { second cycle (domain beaded by } \mathrm{n}): & \begin{array}{l}\text { insertion } \\ \text { truncation } \\ \text { dissimilation }\end{array} & \begin{array}{l}\text { pidi-on } \\ \text { pi.dón }\end{array} & \\ & - & \text { (trigger absent) }\end{array}$

However, Bermúdez-Otero (2013a: 68-71) forestalled this manoeuvre by providing positive evidence that Spanish verb stems do trigger phonological cycles. The argument rests on the observation that Spanish has a phonotactic restriction forbidding hiatus between an unstressed high vocoid and a following nonhigh vowel. In nonalternating tautomorphemic sequences, lexical exceptions to this restriction exist, but they are few and may occur only if both of the following conditions are met (Hualde 1997, 1999).

(i) The high vocoid occupies the first syllable of the word: e.g. exceptional hiatus is possible in [bi.ó.lo.yo] 'biologist', but not in [re.li.xjón] 'religion'.

(ii) Stress falls on the nonhigh vowel or, more rarely, on the immediately following syllable: e.g. exceptional hiatus is possible in [di.á.na] 'Diana', but not in [dja.yo.nál] 'diagonal'.

In contrast, hiatus between an unstressed high vocoid and an immediately following stressed nonhigh vowel is predictable, rather than exceptional, in inflected verbs and in deverbal derivatives like those shown in (25.b).
$\left.\begin{array}{l}\text { a. [pro.nun. } \theta \text { já.mos] 'pronounce.1PL' } \\ \text { [pro.nun. } \theta \text { já.ßle] 'pronounceable' }\end{array}\right\}$
cf. [pro.nún. $\theta$ ja] 'pronounce.3sG' $\left.\begin{array}{l}\text { b. [te.le. } \gamma \text { ra.fi.á.mos] 'telegraph.1PL' } \\ \text { [te.le. } \gamma \text { ra.fi.á.ple] 'telegraphable' }\end{array}\right\}$
cf. [te.le. $\gamma$ ra.fi.a] 'telegraph.3sG' 


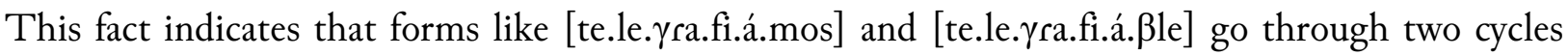
of the stem-level phonology. In the first cycle, triggered by the verb stem, stress is assigned to the high vocoid, resulting in hiatus with the following vowel. In the second cycle, input stress protects the high vocoid from desyllabification.

$$
\begin{aligned}
& \text { UR } \quad\left[{ }^{S \mathcal{L}}\left[{ }^{S \mathcal{L}} \text { pronun } \theta \mathrm{j}-\mathrm{a}\right\rfloor \operatorname{mos}\right. \\
& \text { first cycle pro.nún. } \theta \mathrm{ja} \\
& \text { second cycle } \\
& \text { pro.nun. } \theta \text { já.mos }
\end{aligned}
$$

$$
\begin{aligned}
& {\left[S \mathcal{L}\left[{ }^{S \mathcal{L}} \text { telegrafi-a } \rrbracket \text { mos }\right]\right.} \\
& \text { te.le.gra.fí.a } \\
& \text { te.le.gra.fi.á.mos }
\end{aligned}
$$

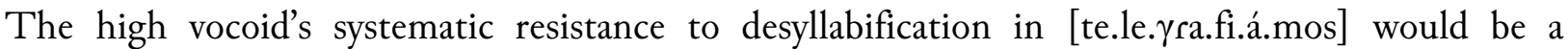
mystery if this inflectional form were derived in a single cycle from underlying /telegrafi-a-mos/: when the high vocoid is housed outside the first syllable of the word, as in this case, desyllabification admits no exceptions unless the high vocoid has a tonic alternant. We must therefore conclude that derivation (24) is incorrect because Spanish verb stems do trigger cycles of the stem-level phonology, as shown in (26).

Myler (2015) attempts to rebut this objection by adopting a different analysis of contrasts

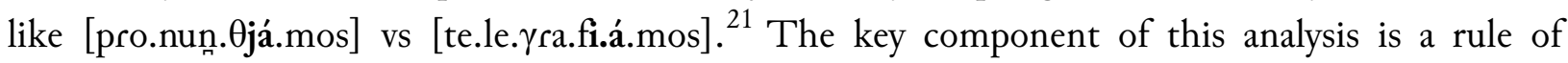
gliding that desyllabifies an unstressed high vocoid before another vowel (Myler 2015: 184). Myler makes two major claims about this gliding rule:

(i) it is insensitive to the stress profile of the base (if any);

(ii) it is conditioned by syntactic category, applying to high vocoids in noun and adjective stems but not in verb stems.

According to Myler, therefore, the contrast between [pro.nun. $\theta$ já.mos] and [te.le. $\gamma$ ra.fi.á.mos] simply reflects an underlying opposition between root-final $/ \mathrm{j} /$ and $/ \mathrm{i} /$. The underlying $/ \mathrm{i} /$ of /telegrafi-a-mos/, he claims, resists gliding not because it bears stress in [te.le. $\gamma r a . f i . a], ~ b u t ~ b e c a u s e$ gliding does not apply to verbs.

In support of claim (i), Myler adduces Cabré \& Prieto's (2006: 222) report that denominal derivatives undergo gliding even when the high vocoid bears stress in the base noun. Cabre \& Prieto base this report on a list of nine putatively denominal derivatives allegedly subject to gliding. In (27) I reproduce this list in full, retaining Cabré \& Prieto's transcriptions and glosses. ${ }^{22}$

a. putative base

$\begin{array}{ll}\text { María } & \text { 'Maria' } \\ \text { sangría } & \text { 'bleeding' } \\ \text { policía } & \text { 'police' }\end{array}$

b. putative derivative

$\begin{array}{ll}\operatorname{Mar}[\text { 'ja }] \text { no } & \text { 'Mariano' } \\ \operatorname{sangr}[\text { 'je]nto } & \text { 'bloody' } \\ \text { polic['ja]l } & \text { 'police-related' }\end{array}$

21 In essence, Myler revives Harris’s analysis (e.g. 1995: §4.1), which took no account of restrictions on the incidence of exceptional hiatus in nonalternating tautomorphemic sequences (cf. Hualde 1997, 1999).

22 Cabré \& Ohannesian (2007: §2.2) list exactly the same nine items. 


$\begin{array}{llll}\text { valía } & \text { 'value' } & \operatorname{val[}[\mathrm{jo}] \text { so } & \text { 'valuable' } \\ \text { manía } & \text { 'peculiarity' } & \operatorname{man}[\text { 'ja]tico } & \text { 'eccentric' } \\ \text { gestoría } & \text { 'agency' } & \operatorname{gestor}[\text { 'ja]l } & \text { 'agency-related' } \\ \text { Rocío } & \text { 'Rocío' } & \operatorname{roc}[\text { 'je]ro } & \text { 'pilgrim to Rocío' } \\ \text { abadía } & \text { 'abbey' } & \operatorname{abac}[\text { 'ja]l } & \text { 'abbey-related' } \\ \text { navio } & \text { 'ship' } & \operatorname{nav}[\text { 'je]ro } & \text { 'shipping' }\end{array}$

However, Cabré \& Prieto's evidence is flawed and does not warrant their assertion. Not one of their nine examples is immune to challenge. In addition, the previous literature does report cyclic transmission of stress-induced hiatus in Spanish denominal derivation.

First, the source of the transcriptions shown in (27.b) is not apparent. Cabre \& Prieto's otherwise admirable study of hiatal high vocoids in Spanish is based on a 246-word questionnaire (2006: 208-210, 236-238). Of the nine putatively denominal derivatives in (27.b), however, only maniático features in this questionnaire. If the transcriptions reflect the authors' intuitions, then they should be treated with circumspection, for Cabré \& Prieto (2006: 210) themselves report that their perceptions diverged from their informants' judgements: 'Typically, we classified as diphthongs vowel sequences that were considered to be hiatuses by the speaker.' My own nativespeaker judgements are sharply different. I fully agree that diphthongs are the only possibility in sangriento, policial, gestorial, and abacial; in contrast, I have hiatuses in valioso, maniático, rociero, and naviero. In the case of Mariano, [ma.jjá.no] sounds fine as the pronunciation of the proper name, but [ma.ri.á.no] is better for the adjective 'pertaining to the Virgin Mary'. My judgements are robustly confirmed by fellow native-speaker linguists: e.g. Antonio Fábregas (personal communication) shares all of my intuitions, except that he prefers a diphthong in valioso. Independent reports of cyclic hiatus in denominal derivatives are of course also found in the published literature: e.g. [es.tí.o] 'summer' [es.ti.á.xe] 'summer drought' (Hualde 1997: 67). Indeed, the received view since Navarro Tomás (1918: 124) has always been that stress on the high vocoid in the base noun does increase the probability of hiatus in the derivative (e.g. Hualde 1997, 1999; Hualde \& Prieto 2002).

Secondly, the derivational relationships suggested by Cabré \& Prieto (2006: 222) are plainly incorrect in at least three cases (sangriento, gestorial, and abacial), and highly questionable in two more (Mariano and valioso):

- Sangriento 'bloody' derives from sangre 'blood', just as sediento 'thirsty' derives from sed 'thirst', and bambriento 'hungry' derives from bambre 'hunger'.

- Gestorial 'administrative' derives from gestor 'administrator' and not from gestoría 'bureaucratic assistance firm'. Like other bases containing the Latinate suffix -or, gestor rejects /-al/ and instead takes /-ial/, which surfaces as [-jál] through regular phonology: cf. [se.nór] 'lord' [se.no.rjál] 'aristocratic'.

- Abacial 'abbatial' derives neither from abadía 'abbey' nor from abad 'abbot', but rather contains an idiosyncratic allomorph of the root $\sqrt{\mathrm{ABAD}}$. Abacial exhibits the full allosemic range of the root: cf. iglesia abacial 'abbey church' with potestad abacial 'abbot's jurisdiction'. 
- Mariano, already discussed above, features in Cabré \& Prieto's (2006: 222) list as a proper name. In the absence of evidence, it is unsafe to assume that a proper name behaves synchronically as a complex item, whatever its origins; cf. the American English data in (28).

\begin{tabular}{lllll} 
non-name & \multicolumn{3}{c}{ name } \\
$\begin{array}{l}\text { mail-er } \\
\text { mann-ing }\end{array}[\mathrm{e}: \partial]$ & 'one who mails' & Mailer [1] [1] & (Hayes 2000: 98) \\
mans.PTCP' & Manning [x] & (Labov 2007: 369)
\end{tabular}

- Valioso 'valuable' has lost its derivational link to valía, whose denotation is now restricted to 'moral or intellectual worth'. The relevance of the pair valía valioso is further undermined by the fact that the token frequency of the putative base is much lower than that of the putative derivative: see the discussion of naviero below.

Two other examples listed by Cabré \& Prieto (2006: 222) raise more subtle, but equally serious, difficulties:

- Policial is always pronounced with a diphthong, and there is no doubt that this adjective is based on the noun policía. However, it may contain the suffix /-ial/, which yields surface [-jál]: cf. [rá $\theta-a]$ 'race' $\sim$ [ra $\theta$-jál] 'racial'. Tellingly, Antonio Fábregas reports that he contrasts [po.li.Өjál] with [po.li.Өi.á.ko], which has the same base.

- Naviero is a particularly interesting case. Both Antonio Fábregas and I pronounce this word with hiatus. Yet almost a century ago Navarro Tomás (1918: 124) reported [jé]. This interspeaker variation is likely to reflect an effect of token frequency: see the Google counts in (29). The cyclic inheritance of semantic and phonological properties is known to be prone to variation when the base has lower frequency than the derivative: see section 3 for discussion.

$$
\begin{array}{lr}
<\text { navío }> & 976,000 \\
<\text { naviero }>\text { and }<\text { naviera }>\quad 1,572,000 \quad \text { (Google hits on 9 July 2014) }
\end{array}
$$

It thus emerges that seven out of the nine data points in (27.b) tell us little or nothing about the cyclic transmission of stress-induced hiatus in Spanish denominal derivation. Cabré \& Prieto's (2006: 222) transcriptions for the remaining two items, maniático and rociero, are certainly invalid for Peninsular dialects such as those spoken by Antonio Fábregas and myself. I conclude that the evidence of (27.b) is severely flawed. In line with authoritative publications like Navarro Tomás (1918: 124) and Hualde (1997: 67), we can at this point confidently reject the proposition that there are no effects of base stress in the syllabification of high vocoids in denominal forms.

Yet, even if this proposition had been true, the problem of the missing cycle would remain. In the framework that Myler (2015) espouses, it would be perfectly possible for high vocoid syllabification to show sensitivity to base stress in inflected verbs and deverbal derivatives, and not in denominal forms. As it happens, this is precisely what Cabré \& Prieto (2006) themselves claim to be the case: their data on verbal inflection and deverbal derivation, which does not suffer from the flaws diagnosed above, provides overwhelming evidence for an effect of base stress. And, 
crucially, a cyclic effect in the phonology of stem-level deverbal forms is all that it takes to render derivations like (24) untenable and so to reassert the problem of the missing cycle with full force. In this sense, the syllabification of high vocoids in denominal items is a mere sideshow. Myler raises the issue solely for the sake of casting a general veil of doubt over derivation (26); but, as we have seen, the flawed testimony of the unreliable witnesses in (27.b) cannot discredit this analysis.

We thus come to the real crux of the matter: Myler's claim that gliding does not apply at all in verb stems. This hypothesis overgenerates for reasons already stated in Bermúdez-Otero (2013a: 70): it incorrectly predicts that, in inflected verbs and deverbal derivatives, a nonalternating unstressed high vocoid can be in hiatus with an immediately following tonic vowel even if it lies arbitrarily far from the left edge of the word. In consequence, Myler (2015: 180, note 8) is compelled to treat the absence of verb forms like *[pa.le.si.á.ðan] as an accidental gap; cf. grammatical [de.te.rjó.ran] 'deteriorate.3PL.PRS.IND'. Yet the nonsyllabic realization of the high vocoid throughout the paradigm of deterior $-a-r$ is predictable; syllabic [i] is categorically excluded in this environment. Observe that stress cannot prevent gliding in this case, since it falls to the right of the high vocoid throughout the paradigm: in the bare stem [deterjós-a], it lands on prethematic [o]. Given this, glided [j] is predictable in accordance with the generalization that forbids hiatal high vocoids unless they occupy the first syllable of the word. Verb forms like *[de.te.ri.ó.ran] and *[pa.le.si.á.ðan] are therefore not accidentally absent; they are systematically ruled out by Spanish phonotactics. This can easily be confirmed by means of straightforward wug tests and through the elicitation of well-formedness judgements about nonce forms.

In conclusion, Myler (2015) fails in his attempt to refute Bermúdez-Otero's (2013a: 68-71) demonstration that Spanish verb stems trigger cycles of the stem-level phonology. Myler's argument cannot draw support from the behaviour of high vocoids in denominal derivatives, and his analysis crucially overgenerates hiatus in inflected verbs and in deverbal derivatives. In consequence, his solution to the problem of the missing cycle collapses: derivations like (24) are untenable. The Spanish diphthongal and third-conjugation alternations continue to challenge single-terminal insertion.

\subsubsection{The parallel cyclic transmission of allomorphy and allosemy}

The fact that the stem-level phonology of Spanish applies in the expected manner over domains defined by verb stems has positive implications for cyclic architectures of grammar. As I show below, Myler's (2015) response to the problem of the missing cycle makes the undesirable prediction that there can be cycles of semantic interpretation without corresponding cycles of phonological interpretation. Conversely, Marantz (2013: 114) and Embick (2014) suggest that the phonology may have its own parochial reasons for running the cyclic phonological rules over a constituent even if the latter does not constitute a spell-dout domain. These proposals abandon the programme of explaining the symmetry of phonological and semantic compositionality in word formation (Marantz 2007: §1). As a result, celebrated contrasts such as ['twinklın] 'instant'vs ['twigklin] 'twinkle.GERUND' (Marvin 2002: 31-32) cease to receive a principled explanation but 
must instead be derived by brute force (Marantz 2013: 114, endnote 3). In this section I argue that we need not resign ourselves to this disappointing outcome: cyclic domains of phonological and semantic interpretation can be brought back into alignment if we reject single-terminal insertion and instead adopt spanning or stem storage.

Myler's position is that Spanish verb stems do constitute spell-out domains; he denies, however, that the rules of the cyclic phonology apply in those domains. In his derivation of the deverbal noun $[\mathrm{N}[\mathrm{V}$ kont-a $]$ ðór $]$ 'counter', for example, there is a spell-out cycle during which the complex $\sqrt{\operatorname{CONT}^{-}} v^{-}$TH is realized as the stem $/$kont $-\varnothing-\mathrm{a} /$. By stipulation, however, the cyclic stress rules do not apply in this domain because it is headed by $v$. Rather, stress assignment has to wait until the next cycle, in which $n^{-}$TH is spelled out as /-dor- $\varnothing /$ (Myler 2015: 176). The stipulation that verb stems are noncyclic for phonological purposes deals with the fact that the vowel of the root fails to diphthongize in the first cycle: cf. [kwént-a] 'count.3SG.PRS.IND'. In the case of or [piðón] (18), pursuing Myler's strategy again involves switching the phonology off in the cycle that spells out $\sqrt{\mathrm{PID}}-v^{-} \mathrm{TH}$ as /pid- $\varnothing-\mathrm{i} /$. This prevents the morphophonological rule of third-conjugation dissimilation (19) from applying to the stem. Dissimilation is turned back on in the next cycle, where $n^{-}$TH is realized as /-on- $\varnothing /$ : see (24).

Although Myler does not overtly discuss the issue, his claim appears to be that, even if Spanish verb stems do not trigger cycles of phonological computation, they do define domains for semantic interpretation: once $\sqrt{\mathrm{CONT}^{-}} v^{-} \mathrm{TH}$ and $\sqrt{\mathrm{PID}}-v^{-} \mathrm{TH}$ have been shipped off to the interfaces, LF can have no way of knowing that PF will carry out vocabulary insertion but will refrain from applying any phonological rules. In a sense, this is correct: as we shall see presently, there is plentiful evidence that Spanish verb stems do define domains for 'allosemic' selection (to use the term popularized by Marantz 2013: 97). The result, however, is that semantic and phonological interpretation are allowed to become decorrelated.

There is no empirical justification for this decorrelation; it is an ad boc expedient that mainstream DM is forced to adopt for purely theory-internal reasons in order to safeguard singleterminal insertion. What the Spanish data reveal, rather, is phonological and semantic interpretation unfolding in perfect lockstep, once it is realized that allomorphy and allosemy are properties of lexemes and not of acategorial roots (Bermúdez-Otero 2013a: 78). To take just one example, consider the root $\sqrt{\text { POBL}}$, descended from Latin populus 'people' and so cognate with English people. This root is shared by two Spanish lexemes: the noun PUEBLO and the verb POBLAR. Each of these lexemes makes its own selection of allomorphs and allosemes. The noun PUEBLO has a single stem of the $o$-class, /pwebl-o/, whereas the verb POBLAR has two stems of the $a$-class, /pwebl-a/ and /pobl-a/: e.g. [pwéßlas] 2SG.PRS.IND [poßlámos] 1PL.PRS.IND. ${ }^{23}$ In parallel, PUEBLO makes a particular cut out of the wide semantic range of the root: it allows two readings, 'ethnic or national group' and 'village'. In contrast, POBLAR picks the alloseme 'to settle,

23 See Bermúdez-Otero (2013a: 78-82) for discussion of the processes of acquisition and change that cause cognate nouns and verbs to have different numbers of stems. 
inhabit, or populate'. Crucially, the allomorphic and allosemic properties of the two lexemes are transmitted with exquisite precision to their derivatives. For example, the noun PUEBLO provides the base for the pejorative adjective [pweßl-er-ín-o] 'villager-like through lack of sophistication'. On the phonological side, [pweßleríno] inherits the unavailability of a root monophthong from PUEBLO, which, as we saw above, is a one-stem noun. If the base noun had afforded a monophthongal stem, this stem woud have been selected for the adjective, as -er-o and -in-o are stem-level suffixes: cf. [pwérta] 'door' $\sim$ [portéro] 'doorman', [serpjénte] 'serpent' $\sim$ [serpentíno] 'serpentine'. On the semantic side, pueblerino inherits the 'village' alloseme. Compare this with a derivative of the verb POBLAR: [poßl-a- $\theta$ jón] 'settlement, population'. This time, the atonic rootvowel surfaces as [o] because POBLAR does supply a monophthongal stem. In addition, población inherits from the base verb the 'settlement' alloseme, and not the 'village' one: Tokyo cannot be described as a pueblo, but it can be described as the largest población on earth. The situation is summarized in (30).

(30)

$\begin{array}{llll}\text { lexeme } & \text { allomorphs } & \text { allosemes } & \text { derivatives } \\ \text { PUEBLO } & \text { /pwebl-o/ } & \text { 'nation', 'village' } & \text { [pweßleríno] '(pej.) villager-like' } \\ \text { POBLAR } & / \text { pwebl-a/, /pobl-a/ } & \text { 'settle, inhabit' } & \text { [poßlaOjón] 'settlement, population' }\end{array}$

There is no decorrelation between phonology and semantics; the two lexemes are domains for both allomorphic and allosemic choices, which they then transmit to their derivatives.

For a more forcible illustration of the same point, I now turn to a set of examples that has received a great deal of attention in the DM literature. It consists of pairs of English words containing the same root and homophonous suffixes, but differing in both phonology and semantics:
a. ['twinklin] 'instant' (e.g. in a twinkling 'in an instant')
['twigklin] 'twinkle.GERUND'
b. ['latnin] 'electrostatic discharge in the atmosphere'
['laitnin] 'lighten.GERUND'
c. cómparable 'similar'
compárable 'that can be compared'

Marvin (2002: 31-41) used this evidence very persuasively to argue for two fundamental hypotheses:

- in word formation, both phonological and semantic interpretation proceed cyclically over domains defined by the constituent structure of words;

and - the domains for phonological and semantic interpretation are coextensive.

The second hypothesis asserts that the same word-syntactic nodes that trigger phonological cycles also define domains for semantic interpretation, and vice versa: being cyclic for phonology entails 
being cyclic for semantics, and vice versa. Marvin highlighted this as a key prediction emerging from Marantz's application of Chomsky's (2001) Phase Theory to word formation: during spellout, the same chunk is shipped off to both the PF and LF interfaces (Marantz 2007). The technical implementation of the analysis assumes the structures shown in (32.a). On the standard assumption that category-determining heads are cyclic, these structures give rise to a one-cycle derivation in the case of ['twinklin] 'instant', and to a two-cycle derivation in the case of ['twigklin] 'twinkle.GERUND': see (32.b). The result is that the gerund inherits the syllabic [1] of the verb ['twinkl] on the PF side, and its eventive semantics on the LF side.

['twinklın] 'instant'

a.

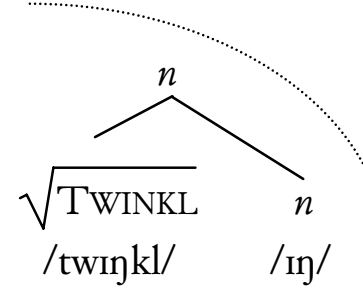

b. $\quad P F$

['twin.klin] 'instant' ['twinklin] 'twinkle.GERUND'

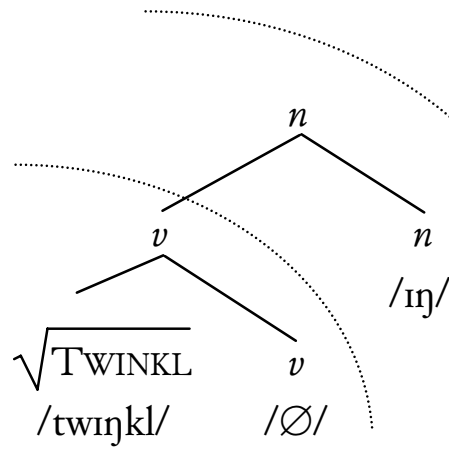

$$
\begin{array}{ll}
\mathrm{PF} & \mathrm{LF} \\
\text { ['twin.kl] } & \text { 'twinkle' } \\
\text { ['twin.kl..I] }] & \text { 'event of twinkling' }
\end{array}
$$

Satisfying though this explanation seemed, it soon became apparent that, under the assumption of single-terminal insertion, wildly incorrect predictions would follow if PF could never see beyond the category-determining head spelled out in a given cycle. For example, there could be no tense-conditioned allomorphy of the type exhibited by English strong verbs: e.g. sing $\sim$ sang. To appreciate this point, assume, in line with the hypothesis of single-terminal insertion, that participation in Ablaut is a property of specific roots such as $\sqrt{\text { SING }}$, and that Ablaut itself is driven by readjustment rules like (23). In that case, principles of cyclic locality like the Readjustment Activity Hypothesis (22) dictate that Ablaut can be triggered only by heads spelled out in the same PF cycle as the root. From this it necessarily follows that inflectional heads like Asp and T must be spelled out in the same cycle as $v$ (Embick 2010). 


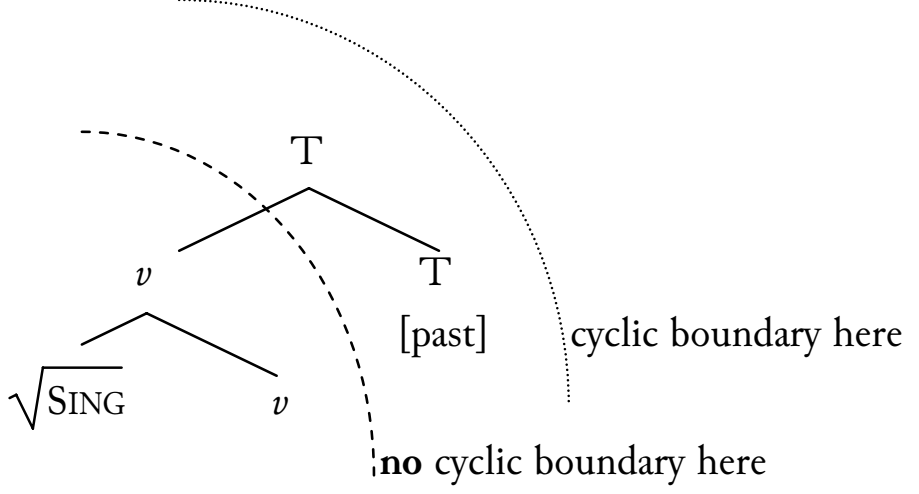

Unfortunately, this widening of spell-out domains destroys Marvin's explanation of the ['twinklin] ['twinklin] contrast. To see this, consider the progressive form of twinkle, as in The stars are twinkling in the sky. This form is exactly homophonous with the gerund, preserving the syllabic [1] of ['twigkl]. Yet, under the assumption that Asp is in the same spell-out domain as $v$, the derivation of the progressive form proceeds in a single cycle, and so its realization should be homophonous with ['twinklin] 'instant': compare (34) with (32).

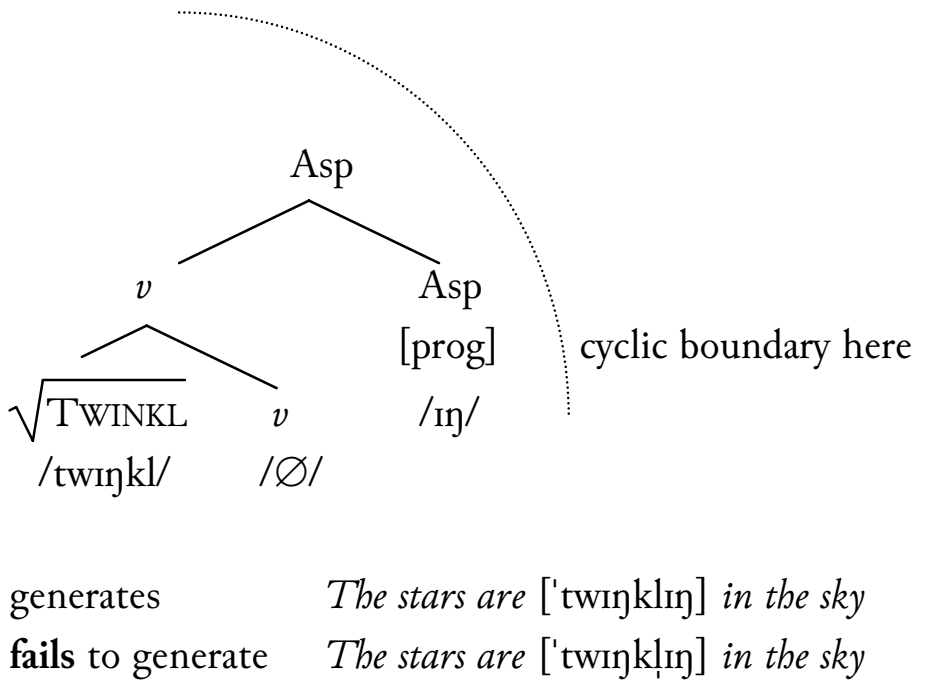

In response to this problem, Marantz (2013: 114, endnote 3) abandons the hypothesis that phonological cyclicity is driven by the phase-theoretic engine of spell-out (cf. Marantz 2007: §1). Instead, he suggests that, even if the progressive form of twinkle triggers a single spell-out cycle in which $\sqrt{\text { TWINKL }}, v$, and Asp are all visible to each other for the purposes of vocabulary insertion, nonetheless the phonology, for reasons known to itself, runs two cycles, the first over $I_{v}$ twinkl- $\varnothing /$, and the second over /Asp 'twinkl-in/. Embick (2014) develops this suggestion further, outlining a theory that distinguishes spell-out cycles ('phase cycles') from phonological cycles (' $\varphi$ cycles').

This is a retrogressive step: explanation has given way to stipulation. But the problem does not end there: saying that the progressive form of twinkle goes through one spell-out cycle and two phonological cycles may take care of the PF side, but what about LF? If the phase-theoretic engine of spell-out submits the whole of (34) to the interfaces at once, then the danger arises that 
the progressive form of twinkle could be assigned an idiomatic interpretation. Marvin's account of ['twinklin] 'instant' is predicated on the assumption that first-cycle readings can be idiosyncratic (see also Arad 2003, Embick \& Marantz 2008). In that case, if the progressive form of twinkle reaches semantics in a single chunk, there is no mechanism to stop this form from having a noncompositional reading, like 'seeing phosphenes'. In consequence, it is necessary to stipulate that semantics too, for reasons known to itself, chooses to run two cycles of interpretation over the single chunk submitted by spell-out. This stipulation is required even if the theory of idiosyncratic readings adopted by Marvin (2002), Arad (2003), and Embick \& Marantz (2008) is wrong (cf. Marantz 2013): insofar as the meaning of ['twinklin] 'twinkle.PRoG' is built compositionally on that of twinkle, we need two cycles of semantic interpretation in any case. The outcome, then, is not one stipulation, but a conspiracy of two stipulations: both phonology and semantics run two cycles over material that spell-out submits in one go.

Most worryingly, there is no grammatical mechanism capable of ensuring that the parochial cycles of phonology and semantics run in sync. Phase Theory assumes the T-model of grammar, and so does not provide a channel of communication from phonology to semantics or vice versa. In consequence, phonology and semantics cannot talk to each other to ensure that they choose to run multiple parochial cycles over single spell-out domains in precisely the same cases.

This retreat from principled explanation to conspiratorial stipulation is disappointing and should be resisted. Instead of accepting such a brute-force solution, we ought to address the true cause of the problem: the hypothesis of single-terminal insertion. We must accordingly reject the claim that /sıy/, /sæy/, /sıy/, and /spy/ are all exponents of the acategorial root $\sqrt{\mathrm{SING}}$. Instead, we must assert that /sin/, /sæy/, and /sıy/ are exponents of the verb SING (or $\sqrt{\operatorname{SING}}-v$ ), and /spy/ is an exponent of the noun SONG (or $\sqrt{\mathrm{SING}^{-}} n$ ). Given this simple premise, tense-driven Ablaut and cycles over verb stems become trivially compatible. Qua verb stems, /sin/ and /sæy/ run through separate cycles of the stem-level phonology by themselves, before competing in the presence of inflectional material: see (17). In frameworks with spanning or stem storage, therefore, we are free to retain Marvin's principled explanation of the contrast between ['twinklin] 'instant' and ['twinklin] 'twinkle.GERUND'/twinkle.PROG'. In cases like cómparable vs compárable (31.c), Marvin's solution is strongly supported by independent evidence. Compárable inherits the stress pattern of the verb compáre. In contrast, the deradical status of compărable is confirmed by the fact that this form exhibits the pattern of 'weak stress retraction' that characterizes -able adjectives based on bound acategorial roots (35): i.e. stress the preantepenultimate syllable when the antepenult is light (Kiparsky 2005b).

$\begin{array}{ll}\text { heavy antepenult } & \text { light antepenult } \\ \text { aménable } & \text { indómĭtable } \\ \text { coméstible } & \text { indúbítable } \\ \text { deléctable } & \text { inéxŏrable } \\ \text { inelúctable } & \text { irréfrăgable }\end{array}$


More generally, multiple-terminal insertion enables us to preserve the fundamental idea that word formation involves parallel cycles of phonological and semantic interpretation. As I shall argue in section 3, there are situations in which this parallelism does break down, but these cases should not be explained by means of unprincipled patches of the grammar's combinatorial engine; rather, they arise through the diachronic interaction of combinatorial computation and lexical storage.

In sum, the Spanish and English evidence reviewed in sections 2.2 and 2.3 reveals that there is an insoluble conflict between three tenets of mainstream DM:

- single-terminal insertion,

- strict inward cyclic locality,

and - coextensive domains of phonological and semantic interpretation.

One of them needs to go. Efforts to preserve single-terminal insertion sacrifice DM's best ideas to save the worst.

\section{We need constituent structure: on the diachronic interaction of computation and storage}

An adequate theory of grammar must account for the exquisite accuracy with which the cyclic transmission of morphophonological properties mirrors the cyclic inheritance of allosemic restrictions in complex expressions like those in (30) and (31). As we have seen, this phenomenon receives a principled explanation if words have hierarchical constituent structure and if the same nodes in this structure define domains for both morphophonological realization and semantic interpretation. Yet, very often, this correlation between part-whole relationships in form and in meaning breaks down. In the following paragraphs I argue that this fact is best understood as arising from the diachronic interaction of computation and storage: when a novel word is first created by grammatical combination, its allomorphy and allosemy are well-aligned; however, historical change may subsequently cause the word to acquire noncompositional phonological or semantic properties, which are stored in its lexical entry and block grammatical computation. The role of blocking in this account is supported by evidence from frequency effects. If this approach generalizes to all the relevant cases, then there will be no need to endow the combinatorial engine of the grammar with the power to generate mismatches between semantic composition and phonological cyclicity. In this section I suggest that, despite appearances to the contrary, so-called bracketing paradoxes like transformational grammarian need not in fact involve rebracketing operations (cf. Sproat 1985). If this line of argument is correct, then discriminative approaches to morphology of the type advocated by Blevins, Ackerman \& Malouf (this volume) are too lax, since they predict that novel words may exhibit allomorphy-allosemy mismatches from the very moment in which they are coined.

English stem-level derivatives like trànsp[ə]rtátion provide a good example of the way in which historical change can cause part-whole relationships in form and in meaning to diverge (Bermúdez-Otero 2012: 34-40; 2013b). The nouns in question have a pretonic sequence of two heavy syllables, of which the second is closed by a sonorant consonant. As noted by Chomsky \& 
Halle (1968: 38-39), whether or not the second syllable bears stress depends on the metrical profile of the noun's base. Thus, the foot-head on the second syllable of the verb imp[j']rt is cyclically transmitted to the derived noun imp[j] rt-átion, whereas comp[ə]nsát-ion inherits the stresslessness of its second syllable from the base cómp[ə] nsàte. This analysis entails that, at the stem level, a syllable closed by a sonorant in the environment $\bar{\sigma} \_f(\ldots)$ must be faithful to its metrical specifications in the input. By Chung's Generalization (Bermúdez-Otero 2012: 31), this predicts that monomorphemic items will display a lexical stress contrast in this position. The prediction proves correct: compare, for example, Pènns[ə]lvánia and Mòz[æ̇]mbíque.

Nonetheless, cyclic stress inheritance often fails in this type of phonological environment. Thus, the nouns in (36.a) exhibit a cyclic stress pattern, but those in (36.b) do not.

\begin{tabular}{|c|c|c|c|c|}
\hline \multirow{3}{*}{ a. } & \multicolumn{2}{|l|}{ base verb } & \multicolumn{2}{|l|}{ derived noun } \\
\hline & $\operatorname{cond}[\dot{\varepsilon}] m n$ & 7.09 & cònd $[\grave{\varepsilon}]$ mnátion & 2.57 \\
\hline & $\operatorname{imp}\left[j^{\prime}\right] r t$ & 5.15 & imp[j] rtátion & 0.62 \\
\hline b. & cons[3́] rve & 1.65 & còns[ว]rvátion & 9.11 \\
\hline & trànsp['́] $r t$ & 7.23 & trànsp[ə]rtátion & 23.54 \\
\hline
\end{tabular}

(The figures denote tokens per million words in the spoken section of COCA.)

This difference cannot be explained simply by analysing instances of còns[ว]rvátion and trànsp[ə]rtátion as deradical (cf. Chomsky \& Halle 1968: 39, footnote 30). Trànsportátion can be pronounced with schwa in the second syllable even in sentences like (37), where it inherits the argument structure of trànsp[j] rt and so must be treated as deverbal.

(37) In Noboa, the plaintiffs argued that the airline's transp[ə]rtation of the human ashes in the valuable cargo section of the aircraft [...] was sufficient to justify a finding of wilful misconduct on the part of the airline.

(International Air Transport Association, The Liability Reporter, 9, February 2006)

Rather, the variation illustrated in (36) is partly caused by differences in relative token frequency between the base and the derived form: cyclic stress inheritance is more likely to fail when the derivative occurs more frequently than the base (Hay 2001, 2003; Kraska-Szlenk 2007: §8.1.2; Collie 2008; Dabouis 2015).

The rise of this frequency effect can easily be explained by adopting two premises: the nonanalytic storage of stem-level expressions (Bermúdez-Otero 2012: 28ff), and a dual-route race model of morphology (e.g. Baayen, Dijkstra \& Schreuder 1997). According to the first premise, nouns like condemnation and transportation have their own lexical entries in which the PHON attribute includes fully prosodified stem-level representations like /,kan.,dem.'neI./n/ and /,tıæns.pə..'ter.Jn/. According to the second premise, the lexicon and the grammar race against each other every time a speaker uses a word like transportation: if lexical search retrieves the 
phonological form of transportation first, online derivation from the verb trànspórt is blocked; otherwise, the grammar computes the pronunciation of the target by concatenating trànspórt- and -átion and applying the stem-level phonology to the result.

In this framework, the balance of two forces determines whether, in the course of historical time, pronunciations with schwa or pronunciations with a full vowel in the second syllable will come to prevail for a particular noun. On the one hand, phonetic factors favour schwa: since the first and third syllables are metrically stronger than the second, the latter is likely to be relatively short in duration. This renders the vowel perceptually similar to schwa (Steriade 2009: 174). As a result, there is a nonzero probability that listeners will misperceive tokens of trànsp[ذ]rtátion as trànsp[ə]rtátion. In accordance with the hypothesis of stem-level nonanalytic listing, such instances of misparsing give rise to lexical entries containing trànsp/ə/rtátion under the PHON attribute. On the other hand, the probability of a full-vowelled realization increases if the noun has a high chance of being derived online from the base verb instead of simply being retrieved from the lexicon. Recall that, in present-day English, the stem-level phonology requires a heavy syllable to be faithful to its input metrical specification in the environment $\bar{\sigma} \_\sigma o(. .$.$) . In$ consequence, online derivation from imp/j’/rt yields imp[j] rtátion.

Crucially, the likelihood that the grammar will win the race against the lexicon varies directly with the token frequency of the base and inversely with the token frequency of the derivative. Assume that frequency boosts the resting activation of lexical entries, which in turn facilitates retrieval. In that case, a base with high token frequency is likely to become available for concatenation relatively fast. If, in turn, the derivative has low token frequency, access to its lexical entry will be relatively slow, and this will make it less likely that online derivation will be blocked. The result is that a derived noun of the type exemplified in (36) is better able to withstand the phonetic bias towards destressing of its second syllable if its own token frequency is lower than that of the base verb. In contrast, cyclic stress preservation has a greater chance of failing when the derivative is more frequent than the base.

As it happens, the relationships of relative frequency that tend to sever the phonological dependence of a derivative on its base also work to undermine the semantic connection between the two (Hay 2003: ch. 5). Thus, historical change may bring about the loss of both phonological cyclicity and semantic compositionality in the same word. The noun inf[ə] rmátion illustrates this outcome: it preserves neither the argument structure nor the metrical bipedality of inf [j] $\mathrm{rm}$.

(38) a. The butler suddenly informed the lady that her guests were in the drawing room.

b. ${ }^{*}$ The butler's sudden information of the lady that her guests were in the drawing room threw her into a panic.

The diachronic evolution of ['twin.klin] 'instant' (31.a) has reached a similar endpoint, allowing ['twig.klin] to be reanalysed as deradical. Yet nothing guarantees that historical change will proceed at the same pace on the phonological and semantic sides. Thus, situations can arise in which part-whole relationships in meaning and in form have become decorrelated: in (37), for 
example, trànsp[ə]rtátion inherits the argument structure of trànsp/j̀/rt but not its bipedality. Nonetheless, it is of the utmost importance to realize that this decorrelation between phonology and semantics is not generated by the grammar's combinatorial engine. On the contrary, our account of the contrast between imp[j] rtátion and trànsp[ə] rtátion assumes precisely that, when such nouns are derived online through the application of grammatical processes, the phonological and semantic properties of the base verb are transmitted in parallel to the derived noun. Thus, phonology-semantics mismatches like (37) arise only through the intervention of lexical storage, which enables lexical entries to register the differential effects of phonological and semantic change.

In sum, the interaction of computation and storage explains why instances of exquisite parallelism between form and meaning, as in (30) and (31), coexist in human language with phonology-semantics mismatches like (37). This proposal makes a variety of empirical predictions. We have seen, for example, that it correctly accounts for the role of relative token frequency in the loss of phonological cyclic effects. Most strikingly, the approach predicts that, when a new word is first coined, part-whole relationships in its form will precisely mirror part-whole relationships in its meaning, as the constituent structure assembled by the grammar's combinatorial engine defines coextensive cyclic domains of morphophonological and semantic interpretation. Misalignments between allomorphy and allosemy may arise only later, as the word ages.

This prediction would appear to be directly challenged by the evidence of bracketing paradoxes. In cases of the transformational grammarian type like (39), for example, considerations of semantic scope seem to suggest the bracketing shown in (39.a), whereas domains for allomorph selection and phonological rule application, as well as prosodic constituency, all point to the bracketing shown in (39.b).
a. [[modern hispan] ist $]$
b. [[modern $][$ hispanist $]]$

To the extent that new paradoxical expressions of this type can be generated productively, such evidence might be taken to indicate that the grammar must have the power to perform rebracketing operations: see e.g. Sproat (1985) for one specific proposal. In turn, this would entail that domains of phonological and semantic interpretation may be misaligned from the very moment that a new linguistic expression is created.

The evidence, however, cannot bear the weight of this conclusion. Rather, we have good reason to doubt that the bracketing [[transformational grammar]ian] correctly describes the structure of this expression at any level of linguistic representation.

- First, tests like one-substitution (40.a) and right-node raising (40.b) support the view that grammarian behaves as a constituent in the syntax.

(40) a. He is a generative grammarian but not a transformational one.

b. I know many generative but few transformational grammarians. 
- Secondly, the bracketing $[[$ modern bispan $]$ ist $]$ fails to predict the fact that bispanist defines a domain for allosemic selection. Observe that the denotation of the noun bispanist is idiosyncratically restricted to scholars studying the culture of Spanish-speaking communities; a population geneticist studying the gene pool of the same communities cannot be described as a hispanist, even though the expression bispanic genes is widely attested. Crucially, modern bispanist preserves this allosemic restriction even in its paradoxical reading: it can refer to a scholar who studies the culture of modern hispanic communities, but not to a geneticist who studies the genes of modern hispanic people.

- Thirdly, in readings like 'practitioner of transformational grammar' and 'student of modern Spanish' the attributive adjectives transformational and modern receive nonintersective interpretations (Larson 1998). However, nonintersective interpretations are also possible when an adjective modifies a monomorphemic noun:

\section{beautiful chef}

a. Intersective interpretation: 'head cook who is beautiful'

b. Nonintersective interpretation: 'person who heads a kitchen beautifully'

This suggests that an analysis based on the syntactic position of affixes may be insufficiently general (Beard 1991: 195, 200). It is likely, rather, that a set of rules of semantic composition that can adequately account for (41.b) will also derive readings like 'student of modern Spanish' without assuming bracketings like (39.a).

In sections 2.3.2 and $3 \mathrm{I}$ have asserted that, when a new word is created, its hierarchical constituent structure defines coextensive domains for phonological realization and semantic interpretation. This explains why, initially, the cyclic inheritance of morphophonological properties precisely mirrors the transmission of allosemic restrictions from smaller to larger constituents. Later, as the word ages, mismatches between morphophonological and semantic cyclicity may arise as the differential effects of phonological and semantic change are registered in lexical entries. Thus, lexical storage plays a crucial role alongside grammatical computation. If something like this is true, it poses a challenge to the discriminative approach to morphology outlined by Blevins, Ackerman \& Malouf (this volume), which asserts that words do not have hierarchical constituent structure. Such frameworks appear too lax, since they do not require allomorphy and allosemy to be well-aligned even in newly created words. ${ }^{24}$

\footnotetext{
24 Blevins, Ackerman \& Malouf (this volume: §2.2) cite morphomic patterns (Aronoff 1994) in support of their position. How much weight should be placed on such evidence is at present unclear. In a review of the current debate on the morphome, Bermúdez-Otero \& Luís (2016) note that several of Aronoffs flagship examples of morphomicity have been challenged and that severe problems of diagnosis remain.
} 


\section{Conclusion}

The five chapters in this part of the volume may all be regarded as grappling with one overarching question: how much of its structuralist inheritance should contemporary morphological theory preserve, and how much should it discard? Pace Archangeli \& Pulleyblank, I believe that we should retain the idea that morphs have underlying representations which phonology maps onto surface representations: for the argument, see Bermúdez-Otero (forthcoming). Pace Blevins, Ackerman \& Malouf, I have argued that we should continue to assume that words have hierarchical constituent structure, generated by combinatorial mechanisms that produce semantically and phonologically compositional outputs. In agreement with Haugen \& Siddiqi, Haugen, and Svenonius, I have argued that we should reject the claim that a morph always realizes a single terminal in word-syntactic structure. These principles, however, will not deliver solutions by themselves; to make progress, we also need to strike the right balance between storage and computation, and between synchrony and diachrony. There is no single key to the problems of morphology.

\section{References}

Ackema, Peter \& Ad Neeleman. 2004. Beyond morphology: interface conditions on word formation. Oxford: Oxford University Press.

Arad, Maya. 2003. Locality constraints on the interpretation of roots: the case of Hebrew denominal verbs. Natural Language and Linguistic Theory 21 (4), 737-78.

Aronoff, Mark. 1994. Morphology by itself: stems and inflectional classes (Linguistic Inquiry Monograph 22). Cambridge, MA: The MIT Press.

Arregi, Karlos \& Andrew Nevins. 2012. Morphotactics: Basque auxiliaries and the structure of spellout (Studies in Natural Language and Linguistic Theory 86). Dordrecht: Springer.

Baayen, Harald, Ton Dijkstra \& Robert Schreuder. 1997. Singulars and plurals in Dutch: evidence for a parallel dual-route model. Journal of Memory and Language 37 (1), 94-117.

Beard, Robert. 1991. Decompositional composition: the semantics of scope ambiguities in "bracketing paradoxes". Natural Language and Linguistic Theory 9, 195-229.

Bermúdez-Otero, Ricardo. 2006. Morphological structure and phonological domains in Spanish denominal derivation. In Fernando Martínez-Gil \& Sonia Colina (eds.), Optimality-theoretic studies in Spanish phonology, 278-311. Amsterdam: John Benjamins.

Bermúdez-Otero, Ricardo. 2010. Stratal Optimality Theory: an overview. http://www.bermudezotero.com/Stratal_Optimality_Theory.htm (accessed on 1 September 2015).

Bermúdez-Otero, Ricardo. 2012. The architecture of grammar and the division of labour in exponence. In Jochen Trommer (ed.), The morphology and phonology of exponence (Oxford Studies in Theoretical Linguistics 41), 8-83. Oxford: Oxford University Press.

Bermúdez-Otero, Ricardo. 2013a. The Spanish lexicon stores stems with theme vowels, not roots with inflectional class features. Probus 25 (1), 3-103. 
Bermúdez-Otero, Ricardo. 2013b. The stem-level syndrome. Paper presented at the Speaker Series of the University of Pennsylvania Linguistics Department, Philadelphia, 11 April 2013. Handout available at http://www.bermudez-otero.com/stemlevel.pdf.

Bermúdez-Otero, Ricardo. 2015. Amphichronic explanation and the life cycle of phonological processes. In Patrick Honeybone \& Joseph C. Salmons (eds.), The Oxford handbook of historical phonology, 37499. Oxford: Oxford University Press.

Bermúdez-Otero, Ricardo. forthcoming. In defence of underlying representations: French adjectival liaison and Romanian morphological palatalization. Probus.

Bermúdez-Otero, Ricardo \& Ana R. Luís. 2016. A view of the morphome debate. In Ana R. Luís \& Ricardo Bermúdez-Otero (eds.), The morphome debate, 309-40. Oxford: Oxford University Press.

Bermúdez-Otero, Ricardo \& Graeme Trousdale. 2012. Cycles and continua: on unidirectionality and gradualness in language change. In Terttu Nevalainen \& Elizabeth Closs Traugott (eds.), The Oxford bandbook of the bistory of English, 691-720. New York: Oxford University Press.

Bloch, Bernard. 1947. English verb inflection. Language 23, 399-418.

Bobaljik, Jonathan David. 2012. Universals in comparative morphology: suppletion, superlatives, and the structure of words. Cambridge, MA: The MIT Press.

Bobaljik, Jonathan David \& Susi Wurmbrand. 2013. Suspension across domains. In Ora Matushansky \& Alec Marantz (eds.), Distributed Morphology today: morphemes for Morris Halle, 185-98. Cambridge, MA: The MIT Press.

Boyé, Gilles \& Patricia Cabredo Hofherr. 2004. Étude de la distribution des suffixes -er/-ir dans les infinitifs de l'espagnol à partir d'un corpus exhaustif. Corpus 3, 237-60. Available online at http://corpus.revues.org/document227.html.

Bye, Patrik. 2015. The nature of allomorphy and exceptionality: evidence from Burushaski plurals. In Eulàlia Bonet, Maria-Rosa Lloret \& Joan Mascaró (eds.), Understanding allomorphy: perspectives from Optimality Theory (Advances in Optimality Theory), 107-76. Sheffield: Equinox.

Bye, Patrik \& Peter Svenonius. 2012. Non-concatenative morphology as epiphenomenon. In Jochen Trommer (ed.), The morphology and phonology of exponence (Oxford Studies in Theoretical Linguistics 41), 427-95. Oxford: Oxford University Press.

Cabré, Teresa \& Maria Ohannesian. 2007. The role of morpheme boundaries in Spanish glide formation. Cuadernos de Lingüistica 14, 1-14.

Cabré, Teresa \& Pilar Prieto. 2006. Exceptional hiatuses in Spanish. In Fernando Martínez-Gil \& Sonia Colina (eds.), Optimality-theoretic studies in Spanish phonology, 205-38. Amsterdam: John Benjamins.

Caha, Pavel. 2009. The nanosyntax of case. PhD dissertation, University of Tromsø.

Chomsky, Noam. 2001. Derivation by phase. In Michael Kenstowicz (ed.), Ken Hale: a life in language, 1-52. Cambridge, MA: The MIT Press.

Chomsky, Noam \& Morris Halle. 1968. The sound pattern of English. New York: Harper \& Row.

COCA. The Corpus of Contemporary American English (COCA): 400+ million words, 1990-present. Created by Mark Davies, Brigham Young University, Provo, UT (2008-). http://www.americancorpus.org/.

Collie, Sarah. 2008. English stress preservation: the case for "fake cyclicity". English Language and Linguistics $12(3), 505-32$.

Dabouis, Quentin. 2015. When stress preservation leads to clash. Ms, Laboratoire Ligérien de Linguistique, Université de Tours. 
Embick, David. 2010. Localism versus globalism in morphology and phonology (Linguistic Inquiry Monographs 60). Cambridge, MA: The MIT Press.

Embick, David. 2012. Contextual conditions on stem alternations: illustrations from the Spanish conjugation. In Irene Franco, Sara Lusini \& Andrés Saab (eds.), Romance languages and linguistic theory 2010: selected papers from 'Going Romance', Leiden, 2010, 21-40. Amsterdam: John Benjamins.

Embick, David. 2014. Phase cycles, $\varphi$-cycles, and phonological (in)activity. In Sabrina Bendjaballah, Noam Faust, Mohamed Lahrouchi \& Nicola Lampitelli (eds.), The form of structure, the structure of forms: essays in honor of Jean Lowenstamm, 271-86. Amsterdam: John Benjamins.

Embick, David. forthcoming. On the targets of phonological realization. In Vera Gribanova \& Stephanie S. Shih (eds.), The morphosyntax-phonology connection: locality and directionality. Oxford: Oxford University Press.

Embick, David \& Morris Halle. 2005. On the status of stems in morphological theory. In Twan Geerts, Ivo van Ginneken \& Haike Jacobs (eds.), Romance languages and linguistic theory 2003: selected papers from 'Going Romance' 2003, Nijmegen, 20-22 November (Current Issues in Linguistic Theory 270), 37-62. Amsterdam: John Benjamins.

Embick, David \& Alec Marantz. 2008. Architecture and blocking. Linguistic Inquiry 39 (1), 1-53.

Fanselow, Gisbert \& Caroline Féry. 2002. Ineffability in grammar. In Gisbert Fanselow \& Caroline Féry (eds.), Resolving conflicts in grammars: Optimality Theory in syntax, morphology, and phonology (Linguistische Berichte Sonderheft 11), 263-3075. Hamburg: Helmut Buske Verlag.

Halle, Morris \& Alec Marantz. 1993. Distributed Morphology and the pieces of inflection. In Kenneth Hale \& Samuel Jay Keyser (eds.), The view from Building 20: essays in linguistics in bonor of Sylvain Bromberger, 111-76. Cambridge, MA: MIT Press.

Halle, Morris \& Alec Marantz. 1994. Some key features of Distributed Morphology. In Andrew Carnie \& Heidi Harley (eds.), Papers on Phonology and Morphology (MIT Working Papers in Linguistics 21), 275-88. Cambridge, MA: MIT Working Papers in Linguistics.

Harris, James W. 1969. Spanish phonology. Cambridge, MA: MIT Press.

Harris, James W. 1995. Projection and edge marking in the computation of stress in Spanish. In John A. Goldsmith (ed.), The bandbook of phonological theory, 867-87. Oxford: Blackwell.

Hay, Jennifer. 2001. Lexical frequency in morphology: is everything relative? Linguistics 39 (6), 1041-70.

Hay, Jennifer. 2003. Causes and consequences of word structure. London: Routledge.

Hayes, Bruce. 2000. Gradient well-formedness in Optimality Theory. In Joost Dekkers, Frank van der Leeuw \& Jeroen van de Weijer (eds.), Optimality Theory: phonology, syntax, and acquisition, 88-120. Oxford: Oxford University Press.

Hockett, Charles F. 1987. Refurbishing our foundations: elementary linguistics from an advanced point of view (Current Issues in Linguistic Theory 56). Amsterdam: John Benjamins.

Hualde, José Ignacio. 1997. Spanish /i/ and related sounds: an exercise in phonemic analysis. Studies in the Linguistic Sciences 27 (2), 61-79.

Hualde, José Ignacio. 1999. Patterns in the lexicon: hiatus with unstressed high vowels in Spanish. In Javier Gutiérrez-Rexach \& Fernando Martínez-Gil (eds.), Advances in Hispanic linguistics: papers from the $2^{\text {nd }}$ Hispanic Linguistics Symposium, vol. 1, 182-97. Somerville, MA: Cascadilla Press.

Hualde, José Ignacio \& Mónica Prieto. 2002. On the diphthong/hiatus contrast in Spanish: some experimental results. Linguistics 40 (2), 217-34.

Jackendoff, Ray. 1975. Morphological and semantic regularities in the lexicon. Language 51 (3), 639-71. 
Jackendoff, Ray. 2002. Foundations of language: brain, meaning, grammar, evolution. Oxford: Oxford University Press.

Kiparsky, Paul. 1994. Allomorphy or morphophonology? In Rajendra Singh \& Richard Desrochers (eds.), Trubetzkoy's orphan. Proceedings of the Montréal roundtable "Morphonology: contemporary responses" (Montréal, September 30 - October 2, 1994), 13-31. Amsterdam: John Benjamins.

Kiparsky, Paul. 2000. Opacity and cyclicity. The Linguistic Review 17 (2-4), 351-65.

Kiparsky, Paul. 2005a. Blocking and periphrasis in inflectional paradigms. In Geert Booij \& Jaap van Marle (eds.), Yearbook of Morphology 2004, 113-35. Heidelberg: Springer.

Kiparsky, Paul. 2005b. Paradigm uniformity constraints. Ms, Stanford University. Available at www.stanford.edu/ kiparsky/Papers/LexConservatism.pdf.

Kiparsky, Paul. 2006. The Amphichronic Program vs. Evolutionary Phonology. Theoretical Linguistics 32 (2), 217-36.

Kiparsky, Paul. forthcoming. The morphology of the Basque auxiliary: thoughts on Arregi \& Nevins 2012. In Vera Gribanova \& Stephanie S. Shih (eds.), The morphosyntax-phonology connection: locality and directionality. Oxford: Oxford University Press.

Kraska-Szlenk, Iwona. 2007. Analogy: the relation between lexicon and grammar (LINCOM Studies in Theoretical Linguistics 38). Munich: LINCOM Europa.

Labov, William. 2007. Transmission and diffusion. Language 83 (2), 344-87.

Larson, Richard K. 1998. Events and modification in nominals. In Devon Strolovitch \& Aaron Lawson (eds.), Proceedings of Semantics and Linguistic Theory (SALT) VIII, 145-68. Ithaca: Cornell Linguistics Circle Publications.

Linares, Rafael Enrique, Antoni Rodriguez-Fornells \& Harald Clahsen. 2006. Stem allomorphy in the Spanish mental lexicon: evidence from behavioral and ERP experiments. Brain and Language 97 (1), 110-20.

Marantz, Alec. 2007. Phases and words. In Sook-Hee Choe (ed.), Phases in the theory of grammar, 191-222. Seoul: Dong In.

Marantz, Alec. 2013. Locality domains for contextual allomorphy across the interfaces. In Ora Matushansky \& Alec Marantz (eds.), Distributed Morphology today: morphemes for Morris Halle, 95-115. Cambridge, MA: The MIT Press.

Marvin, Tatjana. 2002. Topics in the stress and syntax of words. Cambridge, MA: PhD dissertation, MIT.

Merchant, Jason. 2015. How much context is enough? Two cases of span-conditioned stem allomorphy. Linguistic Inquiry 46 (2), 273-303.

Myler, Neil. 2015. Stem storage? Not proven: a reply to Bermúdez-Otero 2013. Linguistic Inquiry 46 (1), 173-86.

Navarro Tomás, Tomás. 1918. Manual de pronunciación española (Publicaciones de la Revista de Filología Española). Madrid: Junta para Ampliación de Estudios e Investigaciones Científicas, Centro de Estudios Históricos.

Nida, Eugene. 1948. The identification of morphemes. Language 24, 414-41.

Orgun, Cemil Orhan \& Sharon Inkelas. 2002. Reconsidering bracket erasure. In Geert Booij \& Jaap van Marle (eds.), Yearbook of morphology 2001, 115-46. Dordrecht: Foris.

Paster, Mary. 2015. Phonologically conditioned suppletive allomorphy: cross-linguistic results and theoretical consequences. In Eulàlia Bonet, Maria-Rosa Lloret \& Joan Mascaró (eds.), Understanding allomorphy: perspectives from Optimality Theory (Advances in Optimality Theory), 218-53. Sheffield: Equinox. 
Pater, Joe. 2009. Morpheme-specific phonology: constraint indexation and inconsistency resolution. In Steve Parker (ed.), Phonological argumentation: essays on evidence and motivation (Advances in Optimality Theory), 123-54. London: Equinox Publishing.

Pullum, Geoffrey K. \& Arnold M. Zwicky. 1991. A misconceived approach to morphology. In Dawn Bates (ed.), WCCFL 10: The proceedings of the Tenth West Coast Conference on Formal Linguistics, 38798. Stanford, CA: CSLI Publications.

Radkevich, Nina. 2010. On location: the structure of case and adpositions. Doctoral dissertation, University of Connecticut.

Roca, Iggy. 2010. Theme vowel allomorphy in Spanish verb inflection: An autosegmental optimality account. Lingua 120 (2), 408-34.

Siddiqi, Daniel. 2009. Syntax within the word: economy, allomorphy, and argument selection in Distributed Morphology (Linguistik Aktuell 138). Amsterdam: John Benjamins.

Sproat, Richard. 1985. On deriving the lexicon. Cambridge, MA: Doctoral dissertation, MIT. Available at http://hdl.handle.net/1721.1/15167.

Staroverov, Petr. 2014. Splitting Theory and consonant epenthesis. Doctoral dissertation, Rutgers University.

Steriade, Donca. 2009. The phonology of perceptibility effects: the P-map and its consequences for constraint organization. In Kristin Hanson \& Sharon Inkelas (eds.), The nature of the word: studies in honor of Paul Kiparsky, 151-79. Cambridge, MA: The MIT Press.

Stewart, Thomas \& Gregory T. Stump. 2007. Paradigm Function Morphology and the morphology-syntax interface. In Gillian Ramchand \& Charles Reiss (eds.), The Oxford handbook of linguistic interfaces, 383-421. Oxford: Oxford University Press.

Stump, Gregory T. 2001. Inflectional morphology: a theory of paradigm structure. Cambridge: Cambridge University Press.

Svenonius, Peter. 2012. Spanning. Ms, University of Tromsø. Available at http://ling.auf.net/lingbuzz/001501.

Trommer, Jochen. 2001. Distributed Optimality. Potsdam: Doctoral dissertation, Universität Potsdam. Available at http://opus.kobv.de/ubp/volltexte/2005/101/pdf/trommer.pdf.

Wescoat, Michael T. 2002. On lexical sharing. Doctoral dissertation, Stanford University.

Wunderlich, Dieter. 1996. Minimalist morphology: the role of paradigms. In Geert Booij \& Jaap van Marle (eds.), Yearbook of Morphology 1995, 93-114. Dordrecht: Kluwer.

Zuraw, Kie. 2010. A model of lexical variation and the grammar with application to Tagalog nasal substitution. Natural Language and Linguistic Theory 28, 417-72. 